\title{
De novo sequencing and analysis of the transcriptome of two highbush blueberry $(V$. corymbosum L.) cultivars 'Bluecrop' and 'Legacy' at harvest and following post-harvest storage
}

Maria Carcamo de la Concepcion

Natural Resources Institute

Daniel James Sargent ( $\square$ dan.sargent@emr.ac.uk)

NIAB EMR https://orcid.org/0000-0002-6686-7147

Nada Surbanovski

NIAB EMR

Richard Colgan

Natural Resources Institute

Marco Moretto

Fondazione Edmund Mach Centro Ricerca e Innovazione

\section{Research article}

Keywords: Blueberry, post-harvest storage, differentially expressed genes, transcriptome analysis, firmness, texture.

Posted Date: July 23rd, 2020

DOI: https://doi.org/10.21203/rs.3.rs-42248/v1

License: (c) (i) This work is licensed under a Creative Commons Attribution 4.0 International License.

Read Full License 


\section{Abstract}

Background: Fruit firmness and in particular the individual components of texture and moisture loss, are considered the key quality traits when describing blueberry fruit quality, and whilst these traits are genetically regulated, the mechanisms governing their control are not clearly understood. In this investigation, RNAseq was performed on fruits of two blueberry cultivars with very different storage properties, 'Bluecrop' and 'Legacy', at harvest, three weeks storage in a non-modified environment at $4{ }^{\circ} \mathrm{C}$ and after three weeks storage at $4{ }^{\circ} \mathrm{C}$ followed by three days at $21^{\circ} \mathrm{C}$, with the aim of understanding the transcriptional changes that occur during storage in cultivars with very different post-harvest fruit quality.

Results: De novo assemblies of the transcriptomes of the two cultivars were performed separately and a total of 39,335 and 41,896 unigenes for 'Bluecrop' and 'Legacy' respectively were resolved. Differential gene expression analyses were grouped into four cluster profiles based on changes in transcript abundance between harvest and 24 days post-harvest. A total of 264 unigenes were up-regulated in 'Legacy' and down-regulated in 'Bluecrop', 103 were down-regulated in 'Legacy' and up-regulated in 'Bluecrop', 43 were up-regulated in both cultivars and 355 were down-regulated in both cultivars between harvest and 24 days post-harvest. Unigenes showing significant differential expression between harvest and following post-harvest cold-storage were grouped into classes of biological processes including stress responses, cell wall metabolism, wax metabolism, calcium metabolism, cellular components, and biological processes.

Conclusions: In total 21 differentially expressed unigenes with a putative role in regulating the response to post-harvest cold-storage in the two cultivars were identified from the de novo transcriptome assemblies performed. The results presented provide a stable foundation from which to perform further analyses with which to functionally validate the candidate genes identified, and to begin to understand the genetic mechanisms controlling changes in firmness in blueberry fruits post-harvest.

\section{Background}

Blueberries belong to the genus Vaccinium which includes the cranberries, lilberries and lingonberries. The genus is a member of the Ericaceae family and its species are common and widespread throughout temperate regions of the world [1]. Most blueberry production comes from cultivars derived from $V$. corymbosum $L$. (highbush blueberry; $2 n=4 x=48$ ), which is native to North America, and are further subclassified as Southern and Northern high-bush according to their chilling requirement [1]. The fresh consumption of blueberries has significantly increased in recent years due to the release of cultivars with exceptional fruit quality which enhances the eating experience and the perception that blueberries offer nutritional and health benefits [2-4]. Although Europe is the third biggest producer of blueberries globally [5] year-round European consumer demand means blueberries are imported in the off season from Southern-hemisphere production regions including Peru and Chile. As blueberries are a fresh product, the long shipping distances from growing regions to consumer markets mean fruit is in transit for up to six weeks. During transit, fruit softening occurs, significantly reducing fruit quality at consumption [6]. 
Fruit texture is the most important quality trait from a consumer perspective [7, 8]. Retention of firmness is widely regarded as the main attribute required for long term storage, and as such it ultimately determines the economic success of blueberry varieties in the marketplace [7, 9]. Softening during storage compromises the final eating quality of the fruit, resulting in fewer repeat purchases by consumers and subsequently reduced sustainability for the blueberry industry. Changes in fruit firmness during post-harvest storage are influenced by many different factors including water loss, the effect of temperature and relative humidity, variation in cell turgor, cell wall composition, the effects of high $\mathrm{CO}_{2}$ and low $\mathrm{O}_{2}$, stem scar size, microstructural changes in cell and tissue layers within the fruit, and skin firmness; all of which have been reported to be genetically regulated [10-14].

Among these factors, water loss, which is primarily influenced by temperature and humidity, has been reported as the main driver of fruit softening $[11,13]$. It has been shown that moisture losses below $1.34 \%$ in blueberry fruits increased fruit firmness during post-harvest storage [13], whilst significant reduction in firmness was observed in fruit where moisture loss was between $4 \%$ and $15 \%[10,13]$. Other factors shown to have a significant impact on fruit softening include cell organization which impacts texture through changes in cell to cell contact, differences in cell types and size, and thinning or degradation of epidermal layers $[11,15,16]$. Softening during post-harvest cold storage has also been shown to be a consequence of changes in cell wall constituents [17] where a reduction in firmness, or increased softening, was positively correlated with an increase of water soluble pectins and weight loss, and a decrease in cellulose and hemicellulose. Giongo et al., 2013 [7] characterized the texture of a range of blueberry cultivars at different developmental and post-harvest stages and identified a number of different mechanical profiles that described the variation in fruit texture. These profiles included measurements of fruit firmness, and a storage index which was used to describe the potential storage performance of the different cultivars. Positive storage index values characterised cultivars that retained good texture during storage, whilst negative values indicated a loss of texture quality during storage.

Owing in part to the tetraploid nature of its genome, genomics resources for cultivated blueberry have not been developed as quickly as in other fruit species such as peach [18] and grapevine[19]. The genome size of the diploid blueberry has been estimated to be in the region of $600 \mathrm{Mb}$ [20] and a genome sequence consisting of 13,757 contigs assembled from publicly-available sequence data for diploid blueberry has been described [21], but was not made available for public scrutiny. More recently however, the first chromosome-scale genome assembly of the cultivated tetraploid highbush blueberry was released [22] consisting of 48 pseudomolecules containing $1.68 \mathrm{~Gb}$ of assembled sequence, and an average of 32,140 protein coding genes per haplotype (128,559 total). The availability of this resource will facilitate further structural and functional genomics studies in cultivated blueberry.

Annotation of the unreleased draft blueberry genome assembly permitted an RNAseq analysis and identification of gene predictions putatively involved in fruit ripening and the biosynthesis of bioactive compounds [21]. Other RNAseq studies in blueberry have characterised changes in gene expression in various tissues under a range of environmental conditions and stresses. These include a study of blueberry root tissue samples with differing tolerance to soil pH changes [23], the identification of genes 
regulating the anthocyanin content of blueberry fruit during ripening [24], and genes associated with changes in fruit firmness during ripening and harvest [25]. Recently, Zhang et al., 2020 [26] reported the analysis of the transcriptome of the blueberry cultivar 'Duke' in response to cold-stress. The authors performed RNAseq experiments on fruit of 'Duke' at harvest and following 30 days storage at 0 degrees $\mathrm{C}$, as well as several physiological assessments. Of the 35,060 unigenes recovered, 1,167 genes were upregulated following cold-storage, whilst 685 were down-regulated and a range of genes with Log2FC above +/-2.0 were annotated, including genes associated with plant hormone transduction, carotenoid biosynthesis, glutathione metabolism, starch and sucrose metabolism, protein processing and porphyrin and chlorophyll metabolism.

In this study RNAseq was used to determine gene expression profiles in fruits of two blueberry cultivars that exhibit different textural change profiles during post-harvest storage [7]; 'Legacy', which retains a firm texture and 'Bluecrop', which becomes soft during storage. Samples were profiled at harvest, following cold storage for 21 days and after 21 days cold storage $\left[4^{\circ} \mathrm{C}\right]$ followed by 3 days storage at room temperature $\left[21^{\circ} \mathrm{C}\right]$. In order to maximise transcript capture for expression analysis, separate de novo unigene assemblies were performed for cvs. 'Bluecrop' and 'Legacy' and RNAseq reads obtained were mapped to each unigene set independently to identify genes differentially expressed during storage in each of the two cultivars. Comparisons were then performed between the datasets of the two cultivars to identify differentially-expressed genes common between the samples, and those that were unique to the two cultivars. A set of differentially-expressed genes with potential importance to post-harvest storage in blueberry were identified and these are discussed in relation to their roles in the retention of fruit firmness and to previous studies.

\section{Results}

\section{RNA sequencing and assembly}

More than 240 million paired-end reads were generated each for both 'Bluecrop' and 'Legacy' using Illumina short-read sequencing. After quality control and trimming, approximately 230 million high quality reads remained for each cultivar (detailed in Additional File 1). Following de novo assembly using Bridger and redundancy reduction with CD-hit, 634,177 'Bluecrop' and 686,520 'Legacy' unigenes were resolved. A total of 233,740 and 249,618 protein coding sequences were identified for 'Bluecrop' and 'Legacy' respectively from the unigene set using GeneMarkS (GMST) and following Blastp analysis, a final unigene set containing 37,711 'Bluecrop' and 37,093 'Legacy' unigenes was obtained (Table 1). After aligning the original reads back to the final unigene sets, the final number of 'Bluecrop' and 'Legacy' unigenes was 39,335 and 41,896 respectively. The mean unigene length was 1,081 bp and 1,057 bp with an N50 of 1,419 and 1,392 for 'Bluecrop' and 'Legacy' respectively. A total of $41.2 \%$ of 'Bluecrop' and $39.7 \%$ of 'Legacy' unigenes were greater than 1,000 bp in length (Table 1). A BUSCO analysis of the final unigene sets revealed an $85.3 \%$ complete set for 'Bluecrop' and an $85.4 \%$ complete set for 'Legacy', with $4.4 \%$ fragmented and $10.3 \%$ missing genes and $3.9 \%$ fragmented and $10.7 \%$ missing genes in the 'Bluecrop' and 'Legacy' datasets respectively. 
Table 1

Summary of the transcript data and assembled unigenes for the 'Bluecrop' and 'Legacy' datasets.

\begin{tabular}{|lll|}
\hline & Bluecrop & Legacy \\
\hline Number of transcripts after Bridger & 1055214 & 1106532 \\
\hline Number of transcripts after CD-HIT & 634177 & 686520 \\
\hline Number of transcripts after GMST & 233740 & 249618 \\
\hline Number of transcripts after BLAST & 34711 & 37093 \\
\hline Number of recovered transcripts & 4624 & 4803 \\
\hline Number of Unigenes & 39335 & 41896 \\
\hline Number of RBBH Unigenes & 27918 & 27918 \\
\hline Total nucleotides of Unigenes & 42539532 & 44300742 \\
\hline Mean length of Unigenes (bp) & 1081.47 & 1057.4 \\
\hline Sequence length > 1000 bp (\%) & 41.15 & 39.67 \\
\hline N50 of Unigenes (bp) & 1419 & 1392 \\
\hline
\end{tabular}

\section{PCA analysis}

A PCA analysis was performed which revealed that the maximum variability between samples was explained by tissue (berry vs. leaf) and cultivar differences (Fig. 1). Data from 'harvest' and '24 days postharvest' tissues clustered more closely to each other than either did to ' 21 days post-harvest', indicating that the $4^{\circ} \mathrm{C}$ temperature at which fruits were sampled after 21 days had a greater effect on gene expression than the post-harvest period itself, and as such, the ' 21 days post-harvest' samples were excluded from further analysis and comparisons were made between the 'harvest' and ' 24 days postharvest' datasets only.

\section{Sequence annotation}

A total of $41.4 \%$ of the 'Bluecrop' and $40.9 \%$ of the 'Legacy' unigenes were annotated using Interproscan, whilst $45.7 \%$ and $45.9 \%$ of the 'Bluecrop' and 'Legacy' unigenes respectively were annotated with Blastp of the Uniprot database. A total of 31,676 and 31,135 gene ontology (GO) terms were associated with 'Bluecrop' and 'Legacy' unigenes respectively. The GO classifications revealed a relatively large number of genes associated with 'cell', 'cell part', 'intracellular part', 'organelle' and cellular processes for both cultivars (Fig. 2). The GO assignments were used to classify the functions of 'Bluecrop' and 'Legacy' transcripts into three categories, cellular component, molecular function and biological process. A few gene families with extremely high read counts were observed encoding repeat domain proteins 
associated with stress processes in plants. Pentatricopeptide, LRR (receptor like kinases containing extracellular leucine rich repeat motifs), and WD proteins in particular were all overrepresented.

\section{Comparison with tetraploid blueberry transcriptome}

A total of 38,937 and 36,415 Blastn alignments were returned for the 'Legacy' and 'Bluecrop' unigene sets when they were queried against the tetraploid $V$. corymbosum 'Draper' [22] gene prediction set.

Alignments were classified by their e-values and their associated alignment length ratios. Almost $80 \%$ of the alignments returned an e-value of 0 and an alignment length ratio greater than 0.9 for both cultivars (Additional file 2) indicating that the 'Bluecrop' and 'Legacy' unigene sets were representative of the gene complement in the reference sequence.

\section{Analysis of differentially expressed genes}

When gene expression within 'Bluecrop' and 'Legacy' samples between harvest and post-harvest was compared separately, 2,370 down-regulated and 937 up-regulated genes were identified in 'Bluecrop', whilst 1,379 down-regulated genes and 542 up-regulated genes were observed 'Legacy'. When the differentially expressed gene (DEG) datasets for 'Bluecrop' and 'Legacy' were compared to each other, 948 genes were down-regulated in both 'Bluecrop' and 'Legacy' between harvest and 24 days post-harvest days post-harvest, a further 1,422 genes were shown to be down-regulated only in 'Bluecrop' and 431 genes were down-regulated only in 'Legacy'. A total of 252 genes were identified that were up-regulated in both 'Bluecrop' and 'Legacy', whilst 685 genes were up-regulated only in 'Bluecrop' and a further 290 were up-regulated only in 'Legacy' (Fig. 3).

DEGs were clustered into four model profiles based on the expression levels in 'Bluecrop' and 'Legacy' when comparing samples at harvest to samples 24 days post-harvest. Between harvest and 24 days post-harvest, a total of 264 DEGs were up-regulated in 'Legacy' but down-regulated in 'Bluecrop', 103 DEGs were down-regulated in 'Legacy' and up-regulated in 'Bluecrop', whilst 43 were up-regulated in both cultivars and 355 were down-regulated in both cultivars (Fig. 4).

\section{Identification of genes associated with physiological changes during post-harvest storage}

A total of $170(5.14 \%)$ genes that were differentially expressed between harvest and post-harvest in 'Bluecrop' and 59 (3.10\%) in 'Legacy' were characterized into corresponding KEGG pathways. DEGs were categorized into 61 pathways for 'Bluecrop' and into 50 pathways for 'Legacy'. The categories with containing larger numbers of DEGs annotated were amino acid metabolism, carbohydrate metabolism and metabolism of cofactors and vitamins for both cultivars. These pathways were followed by energy metabolism in 'Bluecrop' and by nucleotide metabolism in Legacy' (Fig. 5).

Table 2 details 21 DEGs identified that have a potential role in regulating changes in post-harvest firmness when comparing 'Bluecrop' and 'Legacy'. The unigenes clustered into the following classes; 
genes associated with biotic and abiotic stress tolerance (Unigene 13622, Unigene 3661); ethylene regulation (Unigene 7737 and Unigene 13947); redox and respiration metabolism (Unigene 10455, Unigene 13622, Unigene 13959 and Unigene 22338); solute transport (Unigene 20943); calcium transport and signalling (Unigene 13589); cell wall metabolism and structure (Unigene 6781, Unigene 3134, Unigene 22777, Unigene 6494, Unigene 21016, Unigene 8703 and Unigene 9136); and synthesis/degradation of wax compounds (Unigene 6657, Unigene 13672, Unigene 8556 and Unigene 12307) (Fig. 6). 
Table 2

Detail of the 21 differentially-expressed unigenes identified as having a potential role in regulating changes in post-harvest firmness.

Unigene ID
Down regulated in BC and LG

\begin{tabular}{llllll} 
Unigene_7737 & -5.53 & $\begin{array}{l}7.80 \mathrm{E}- \\
06\end{array}$ & IPR001471 & AP2/ERF & $\begin{array}{l}3.15 \mathrm{E}- \\
26\end{array}$ \\
\hline Unigene_3661 & -4.87 & $\begin{array}{l}5.60 \mathrm{E}- \\
06\end{array}$ & IPR003657 & $\begin{array}{l}\text { WRKY domain } \\
\text { superfamily }\end{array}$ & $\begin{array}{l}4.10 \mathrm{E}- \\
24\end{array}$ \\
\hline Unigene_13959 & -3.77 & $\begin{array}{l}6.92 \mathrm{E}- \\
08\end{array}$ & IPR001117 & $\begin{array}{l}\text { Multicopper } \\
\text { oxidase-cupredoxin }\end{array}$ & $\begin{array}{l}4.40 \mathrm{E}- \\
23\end{array}$ \\
\hline Unigene_13589 & -2.95 & $\begin{array}{l}1.50 \mathrm{E}- \\
05\end{array}$ & IPR006769 & Calcium uniporter & $\begin{array}{l}3.90 \mathrm{E}- \\
52\end{array}$ \\
\hline Unigene_6781 & -2.93 & $\begin{array}{l}3.68 \mathrm{E}- \\
05\end{array}$ & IPR000757 & $\begin{array}{l}\text { Xyloglucan endo- } \\
\text { transglycosylse }\end{array}$ & $\begin{array}{l}4.80 \mathrm{E}- \\
63\end{array}$ \\
\hline Unigene_3134 & & & $\begin{array}{l}\text { Glycoside } \\
\text { hydrolase fam 17 }\end{array}$ & $\begin{array}{l}1.50 \mathrm{E}- \\
13\end{array}$ \\
\hline
\end{tabular}

\section{Up regulated in $B C$ and $L G$}

\begin{tabular}{|c|c|c|c|c|c|}
\hline Unigene_13622 & 4.79 & 0.0008 & IPR001878 & Zinc finger family & $\begin{array}{l}7.20 \mathrm{E}- \\
04\end{array}$ \\
\hline Unigene_6657 & 1.285 & $\begin{array}{l}6.22 \mathrm{E}- \\
05\end{array}$ & IPR001330 & Terpenoid cyclase & $\begin{array}{l}2.90 \mathrm{E}- \\
08\end{array}$ \\
\hline Unigene_10455 & 1.284 & 0.00085 & IPR001128 & Cytochrome P450 & $\begin{array}{l}1.40 \mathrm{E}- \\
12\end{array}$ \\
\hline Unigene_20943 & -2.05 & 0.00057 & IPR025886 & $\begin{array}{l}\text { Phloem protein 2- } \\
\text { like }\end{array}$ & $\begin{array}{l}4.70 \mathrm{E}- \\
37\end{array}$ \\
\hline Unigene_20725 & -1.98 & $\begin{array}{l}8.16 \mathrm{E}- \\
06\end{array}$ & IPR006045 & Cupin 1 & $\begin{array}{l}1.40 \mathrm{E}- \\
34\end{array}$ \\
\hline
\end{tabular}

\section{Up regulated in $L G$ and down regulated in $\mathrm{BC}$}

\begin{tabular}{llllll|} 
Unigene_23277 & -7.69 & $\begin{array}{l}1.10 \mathrm{E}- \\
05\end{array}$ & IPR014044 & CAP domain & $\begin{array}{l}6.40 \mathrm{E}- \\
15\end{array}$ \\
\hline Unigene_13947 & -7.18 & $\begin{array}{l}5.11 \mathrm{E}- \\
06\end{array}$ & IPR001471 & AP2/ERF & $\begin{array}{l}1.40 \mathrm{E}- \\
11\end{array}$ \\
\hline Unigene_22777 & & & & $\begin{array}{l}2.30 \mathrm{E}- \\
06\end{array}$ \\
\hline Unigene_13672 & -6.09 & 0.00013 & IPR006706 & Extensin & $\begin{array}{l}1.40 \mathrm{E}- \\
\end{array}$ \\
& -5.31 & $\begin{array}{l}2.12 \mathrm{E}- \\
05\end{array}$ & IPR001906 & Terpene synthase &
\end{tabular}




\begin{tabular}{|c|c|c|c|c|c|}
\hline Unigene ID & LogFC & Pvalue & Interpro ID & Description & Ealue \\
\hline Unigene_22238 & -3.01 & 0.0003 & IPR001128 & Cytochrome P450 & $\begin{array}{l}1.20 \mathrm{E}- \\
08\end{array}$ \\
\hline \multicolumn{6}{|c|}{$\begin{array}{l}\text { Down regulated in } L G \text { and up } \\
\text { regulated in } B C\end{array}$} \\
\hline Unigene_12307 & 4.41 & $\begin{array}{l}7.33 \mathrm{E}- \\
06\end{array}$ & IPR001906 & Terpene synthase & $\begin{array}{l}8.90 \mathrm{E}- \\
45\end{array}$ \\
\hline Unigene_6494 & 3.85 & 0.00074 & IPR004993 & GH3 family & $\begin{array}{l}1.50 \mathrm{E}- \\
93\end{array}$ \\
\hline Unigene_21016 & 2.693 & 0.00014 & IPR007118 & Expansin & $\begin{array}{l}5.50 \mathrm{E}- \\
31\end{array}$ \\
\hline Unigene_8703 & 2.54 & $\begin{array}{l}2.77 \mathrm{E}- \\
06\end{array}$ & IPR000743 & $\begin{array}{l}\text { Glycoside } \\
\text { hydrolase fam } 28\end{array}$ & $\begin{array}{l}1.30 \mathrm{E}- \\
63\end{array}$ \\
\hline Unigene_8556 & 2.42 & $\begin{array}{l}1.44 \mathrm{E}- \\
06\end{array}$ & IPR009721 & $\begin{array}{l}\text { O-acytransferase } \\
\text { WSD } 1\end{array}$ & $\begin{array}{l}3.40 \mathrm{E}- \\
22\end{array}$ \\
\hline
\end{tabular}

\section{Validation of differentially expressed genes by quantitative real-time PCR}

In the RNAseq dataset, unigene_8556 was upregulated in 'Bluecrop' and down-regulated in 'Legacy' between harvest and 24-days post-harvest, unigene_22238 was down-regulated in 'Bluecrop' and upregulated in 'Legacy' between harvest and and 24-days post-harvest, unigene_20943 was upregulated in both 'Bluecrop' and 'Legacy' between harvest and and 24-days post-harvest, and unigene_3134 was down-regulated in both 'Bluecrop' and 'Legacy' between harvest and and 24-days post-harvest (Table 2). Patterns of gene expression following analysis by qRT-PCR were in general agreement with the results from the RNAseq analysis and a linear regression analysis calculating Pearson's correlation factor revealed a strong correlation $\left(R^{2}=0.98 ; p \leq 0.001\right)$ between the log fold-change values observed in the RNAseq data and those observed in the qRT-PCR data (Fig. 7).

\section{Discussion}

Here we present analyses of gene expression changes that occurred in the fruit of two blueberry cultivars, 'Bluecrop' (known for poor firmness retention) and 'Legacy' (known for good firmness retention) during post-harvest storage. Whilst a genome reference sequence for tetraploid blueberry cultivar 'Draper' recently became available [22], which provides a reliable genomic resource for transcriptomic analysis, separate de novo transcriptome assemblies were performed here for 'Bluecrop' and 'Legacy' to avoid multiple-and/or mis-alignments within unigenes produced from a hybrid or reference assembly. Overall, the number of transcripts the 'Legacy' and 'Bluecrop' unigene sets resolved was 41,896 and 39,335 for respectively, comparable to those of the published genome that contained an average of 32,140 gene 
predictions per haplotypes, and the majority of the assembled transcripts returned highly similar, or identical matches to predicted genes within the 'Draper' reference genome [22].

The data presented here revealed that cell, cell part, intracellular, membrane-bound organelle part, cellular and metabolic processes, and catalytic activity were the most represented GO categories within the assembled unigene set. These categories were strongly represented in other studies of 'Bluecrop' [27, 28] as well as in studies of the cultivars 'Northland' [24], 'O'Neal' [21] and 'Duke' [26]. The vast majority of factors affecting post-harvest quality are under strong genetic control [29] and 'Bluecrop' and 'Legacy' previously displayed significant differences in their response to prolonged periods of low-temperature post-harvest storage [7], resulting in very different post-storage texture profiles of the two cultivars. A recent study of Zhang et al., 2020 [26] used the cultivar 'Duke' which previously displayed texture characteristics very similar to 'Legacy' [7] at harvest, but which displayed a significant decline in texture during post-harvest storage. The analysis of differentially expressed genes in 'Duke' identified 1,167 upregulated, and 685 down-regulated genes following 30 days storage at 0 degrees $C$, which contrasted to the 2,370 down-regulated and 937 up-regulated, and 1,379 down-regulated and 542 up-regulated genes in 'Bluecrop' and 'Legacy' respectively following 21 days storage at $4{ }^{\circ} \mathrm{C}$ and three days at $18^{\circ} \mathrm{C}$ in this study.

Here, a greater number of down and up regulated genes was observed in 'Bluecrop' than 'Legacy', suggesting 'Bluecrop' fruit is less well adapted to the physiological stresses associated with prolonged storage at $4^{\circ} \mathrm{C}$ and subsequent shelf life $\left(21^{\circ} \mathrm{C}\right)$ than 'Legacy', as reflected in a greater decline in fruit quality and texture attributes observed in 'Bluecrop' over 'Legacy' [7]. Numerous DEGs associated within diverse cell, molecular, and biological pathways were identified as candidate unigenes with a potential role in firmness changes during storage in this study. Most of the DEGs observed between harvest and post-harvest in 'Bluecrop' and in 'Legacy' were predominantly categorized into amino acid metabolism, carbohydrate metabolism and cofactor and vitamins metabolism, followed by energy metabolism in 'Bluecrop' and by nucleotide metabolism in 'Legacy'. Furthermore, most of the DEGs identified between harvest and post-harvest between both cultivars were putatively involved in cell wall metabolism, composition of the skin wax layer, adaptation to abiotic stress and solute transport. Zhang et al., 2020 [26] found membrane lipid metabolism, proline, glutathione and flavonoid metabolism, and hormone biosynthesis and signal transduction as the main pathways in which genes were differentially expressed in 'Duke', during storage at $0^{\circ} \mathrm{C}$. Whilst many of the categories of DEGs observed were similar between the two studies, the differences observed in gene expression profiles between those reported here for 'Bluecrop' and 'Legacy', and those reported for 'Duke' most probably reflect the differences in the temperature storage protocols employed and most importantly differences in the point of sampling between the two studies. The post-harvest sampling conditions of [26] more closely resembled the sampling point in this investigation immediately following post-harvest storage when fruit was still at $4^{\circ} \mathrm{C}$. Zhang et al., 2020 [26], used a temperature of $0^{\circ} \mathrm{C}$, and whilst that has also been used in other blueberry studies to compare the fruit quality including firmness at different temperatures and days postharvest $[10,11]$, it is not representative of temperatures in retail or home refrigeration settings. 
Scrutiny of the differentially expressed transcripts in 'Bluecrop' and 'Legacy' was focussed on genes that could have played a putative role in the stress response during post-harvest cold-storage, and genes that could play a role in the retention of texture and fruit quality. Previous studies have shown that genes involved in determining the composition of the wax layer [bloom] in blueberry, as well as those involved in cell wall metabolism, adaptation to biotic or abiotic stress, calcium and solute transport could all play a role in maintaining good fruit quality during post-harvest storage, and from these classes, a set of 21 differentially-expressed candidate genes were characterised.

\section{Epicuticular wax metabolism}

The waxy layer representing the bloom of blueberries is a key protective mechanism against a range of abiotic stresses, including moisture loss and temperature fluctuations, and has been shown to reduce deterioration in fruit quality during post-harvest storage [31]. Variations in the composition of the wax compounds in plant cuticles can affect their mechanical properties under storage [35-37] and these variations have been correlated with textural changes in blueberry [38], pepper and tomato [39-41] fruits during storage. Unigene 8556 shown to have high homology to wax ester synthase/diacylglycerol acyltransferase (WSD1), an enzyme which catalyses the synthesis of wax ester compounds in the stem, flowers and leaves of Arabidopsis [42]. Acyltransferase genes have been reported to be strongly upregulated in Arabidopsis in response to abiotic/biotic stress [43] and in Euruca vesicaria seedlings in response to drought stress [44]. 'Bluecrop' softens more rapidly during storage than 'Legacy' [7], indicating a greater rate of moisture loss in 'Bluecrop' fruits during storage [12]. Here, unigene 8556 was highly down-regulated in 'Legacy', but up-regulated in 'Bluecrop', suggesting fruit of 'Bluecrop' may be triggering stress response pathways and increasing wax production in response to moisture loss during extended exposure to low temperatures and reduced \% relative humidity experienced in post-harvest storage.

\section{Cell wall metabolism under post-harvest storage}

Changes in cell wall structure during development and ripening occur due to degradation of cell wall constituents primarily through the disassembly of the cellulose-hemicellulose network [7, 45-47]. The cellulose and hemicellulose matrix comprise microfibrils linked by hydrogen bonds, that increase the strength of the cell wall. In addition, a pectin matrix interlaces the cellulose-hemicellulose backbone conferring cell wall adhesion [25]. Thus, cell wall modifications and disassembly form part of the regulation of fruit softening, which is a process that has been well characterised in blueberries $[17,32$, 48], apple [49], peach [50], strawberries [51, 52] and tomatoes [53, 54].

Glycoside hydrolases have been reported to affect blueberry firmness during ripening and post-harvest stages $[25,26]$ and their enzymatic activity depends on their specificity to individual carbohydrate components forming the cellulose (homopolymer of glucose) and hemicellulose (xylans, glucans, xyloglucans, callose, mannans and glucomannans) structures $[14,55,56]$. In this investigation, homologues of three glycoside hydrolases; GH17 [Unigene 3134), GH3 (Unigene 6494) and GH28 (Unigene 8703) were shown to be differentially-expressed during post-harvest cold-storage. The GH17 
family encodes endoglucanases which degrade cellulose structures (56) and play a role in cell wall degradation in blueberry fruit and banana during ripening stages $(25,57)$. Down-regulation of unigene 3134 (GH17) in 'Bluecrop' and 'Legacy' suggests a reduction in activity of this glycoside hydrolase during cold storage, supporting the findings of $[25,46]$ who reported reduced glycoside hydrolase activity in blueberry fruits during cold storage. Reduction in activity may be purely temperature related or possibly an adaptation mechanism triggered in both cultivars in response to post-harvest cold-storage $[25,46]$. $\mathrm{GH} 3$ is a xylosidase enzyme [56] with a role in degrading cell walls and contributing to softening in blueberry fruits [14, 48], whilst GH28 showed high homology to a polygalacturonase enzyme which degrades pectin by hydrolysing the homogalacturonan backbone of the cell wall [58]. This family of enzymes has been shown to be upregulated during post-harvest storage and to a play a role in the softening of blueberry fruits and cell wall degradation [32]. Both GH3 (Unigene 6494) and GH28 (unigene 8703) were highly upregulated in 'Bluecrop' and down regulated in 'Legacy' during cold storage and thus may play a role in faster cell wall degradation in 'Bluecrop', leading to a greater degree of softening.

The role of expansin proteins in cell wall loosening has been well characterised in Arabidopsis [59], tomato [60, 61], strawberry [62-64], peach [65] and kiwi fruits [66] where its activity is upregulated during the softening of ripening fruits [67]. Expansins initiate cell wall loosening and extension through the breakage of hydrogen bonds between cellulose and hemicellulose molecules, in particular xyloglucans $[68,69]$, and their expression is regulated by cross-talk between many plant growth regulators including abscisic acid, indol-3-acetic acid, auxins, brassinosteroids, cytokines, ethylene [67]. Expansin activity has been shown to be enhanced by low $\mathrm{pH}$, and low temperatures in an absence of an ethylene peak during storage [66]. Unigene 21016 was shown to be highly upregulated in 'Bluecrop' and down regulated in 'Legacy' during post-harvest storage, suggesting that expansins expression in 'Bluecrop' may contribute to the increased fruit softening observed by Giongo et a., 2013 [7], as has been reported in kiwi [66] and in tomato [61], where overexpression of expansins produced softer fruit and silencing was correlated to an increase of firmness and extended shelf life.

\section{Abiotic stress and solute transport}

Adaptation to abiotic stress in plants include the control of cell turgor, the induction of cell signalling pathways, an increase in respiration rates and deployment of protective mechanisms against Reactive Oxygen Species (ROS). The APETALA2/ETHYLENE RESPONSE FACTOR (AP2/ERF) is one of the mediators to plant external abiotic responses and developmental processes [70-73], and has been reported to regulate cold adaptation responses in the flower buds of 'Bluecrop' [74], and in cold-stored blueberry fruit of 'Duke' [26]. Unigene 7737 and Unigene 13947 display high homology to AP2/ERF and were found in differentially regulated clusters in this investigation, suggesting that members of this family of transcription factors may be repressed or induced under the same environmental conditions. AP2/ERF homologs in potato (CIP353) conferred low-temperature acclimation to tubers exposed to longterm cold-storage [72], whilst in tomato the overexpression of PTi4 encoding an AP2/ERF induced a family of expansin genes linked to roles in cell wall integrity [75]. AP2/ERF genes have also been reported to regulate the adaptation to osmotic, water stress and drought tolerance in Arabidopsis [76], and osmotic 
differences between protoplast and the apoplast have been shown to drive changes in turgor pressure in plant cells [77], changes which are linked to post-harvest softening in apple [78] and softening in blueberries $[10,12,15]$. 'Legacy' exhibits a greater retention of firmness than 'Bluecrop' during postharvest cold-storage [7] and unigene 13947 was upregulated in 'Legacy', and down-regulated in 'Bluecrop' suggesting that its expression may play a role in the maintenance of firmness in blueberry fruits during post-harvest cold-storage.

The mitochondria play an important function in buffering cytoplasmic calcium, with mitochondrial calcium uniporters (MCU) acting as calcium sensors and active channel protein for calcium uptake [30, $79,80]$. Mitochondrial uptake plays a role in ATP synthesis and regulating calcium concentration in the cytoplasm [Ca $]_{\text {cyt }}$ which is essential for regulating its role as a secondary messenger in response to abiotic stress. Moreover, $[\mathrm{Ca}]_{\text {cyt }}$ plays a role in regulating fruit quality, specifically by increasing the resilience of fruit to low temperature stress by enhancing the energy status of the cells and maintaining osmotic conditions [81]. Unigene 13589 displayed homology to mitochondrial calcium uniporters [MCU] and was down regulated during post-harvest storage for both cultivars, which may cause loss of mitochondrial function and reduced cellular calcium uptake during post-harvest cold-storage, contributing to fruit quality deterioration during storage.

\section{Conclusions}

Transcriptional changes during post-harvest storage in 'Bluecrop' and in 'Legacy' occur in genes with roles in catalytic activity primarily located in the cell, intracellular parts and membrane-bounded organelles. Additionally, differential expression was observed in genes involved in cell wall metabolism, synthesis of wax compounds and biotic and abiotic stress between harvest and post-harvest in the two cultivars studied. Identification of a set of differentially regulated candidate genes that may have a role in the observed differences in post-harvest fruit quality reported between 'Bluecrop' and 'Legacy' provides a strong foundation for future focussed studies of the role of these genes in relation to specific physiological changes that occur during post-harvest cold-storage in blueberry fruits.

\section{Materials And Methods}

\section{Plant material}

Three plants each of two Northern highbush blueberry ( $V$. corymbosum) cvs. 'Bluecrop' and 'Legacy', were selected for study as they displayed very different textural changes during post-harvest storage [7]. The plants were grown in substrate under tunnels on the Driscoll's test-plot at East Malling, UK and eight-yearold plants with a recorded crop load of more than six kg per year were used for study. Fruits were harvested by hand from both cultivars on the same date and stored at $4{ }^{\circ} \mathrm{C}$ in a non-modified environment for 21 days following which they were removed from cold storage and maintained for a further three days at $21^{\circ} \mathrm{C}$. Berry tissue was collected immediately following harvest; at 21 days postharvest, immediately following removal from $4^{\circ} \mathrm{C}$ cold-storage, and at 24 days post-harvest, following 
three days at $21^{\circ} \mathrm{C}$. Sampled berries were snap frozen in liquid nitrogen and stored at $-80^{\circ} \mathrm{C}$ until use. Three biological replicates were sampled, each of which comprised a random selection of four berries from each sampling point for each cultivar. In addition, one sample of leaf tissue from each cultivar was collected comprising a random selection of four immature unexpanded leaves, snap frozen in liquid nitrogen and stored at $-80^{\circ} \mathrm{C}$ until use.

\section{RNA preparation, library construction, and RNA sequencing}

Each berry and leaf sample was ground to a fine powder under liquid nitrogen using a mortar and pestle and the powder was collected in $2 \mathrm{ml}$ sampling tubes (Eppendorf $\AA$ ) which were then stored at $-80^{\circ} \mathrm{C}$ until RNA extraction was performed. Total RNA was extracted using the Spectrum ${ }^{\text {TM }}$ Plant Total RNA kit (Sigma Aldrich) according to protocol A in the manufacturer's instructions. The concentration and purity of the resultant RNA was measured using a QIAxpert spectrophotometer (Qiagen). The integrity of the RNA was determined using a qubit 4.0 fluorimeter (Thermofisher Scientific) and samples with RNA integrity number (RIN) values above 6.3 were submitted for RNA-SEq. Library preparation was performed for the 18 fruit samples and two leaf samples using the NEB Next® ultra RNA library prep kit (Biolabs, Inc.) and 150-bp paired-end sequencing was performed by NovoGene Inc (China) using the HiSeq2500 platform to yield a minimum of $5.9 \mathrm{~GB}$ of data per sample.

\section{De novo transcriptome assembly and functional annotation}

Raw Illumina reads were cleaned and filtered using Trimmomatic version 0.36 (82), trimming sequence with an average quality below 15 in a four bp sliding window. Reads shorter than $36 \mathrm{bp}$ in length following trimming were removed from further analysis. Read QC was performed using Fast QC version 0.11.7 and de novo assembly of transcripts was done separately for each cultivar using Bridger version 2014-12-01 [83] with default parameters. CD-HIT [84] was then used with a threshold $=0.99$ on 'Bluecrop' and 'Legacy' transcripts separately to reduce redundancy, and GeneMarkS [85] (GMST) was used to predict protein coding regions of each of the transcript sets using default parameters. Align-back of the original reads to the final unigenes revealed $33 \%$ of the raw reads that did not map to the unigene set. These reads were mapped back to the unigenes that were removed from the dataset following the analysis with GMST and unigenes to which more than 50 reads mapped were replaced in the final unigene sets.

The 'Bluecrop' and 'Legacy' unigene sets obtained from GMST were used as queries for Blastp (86) against the diploid blueberry transcriptome

(https://bitbucket.org/lorainelab/blueberrygenome/src/468455807e4b?at=master), Kiwi transcriptome (http://bioinfo.bti.cornell.edu/cgi-bin/kiwi/download.cgi) and Viridiplantae (Uniref100). Only sequences with an alignment length $\geq 70 \%$ with respect to the database sequence and a sequence similarity $\geq 70 \%$ were retained for further analysis.

\section{Analysis of Unigene expression}


Trimmed reads of each sample and treatment were aligned to the 'Bluecrop' and 'Legacy' de novo transcriptome assemblies using Bowtie2 (version 2.3.4) [87] and the read counts for each sample were calculated using featureCounts (1.6.0) [88]. Differential expression analysis was carried out using the Limma empirical Bayes analysis pipeline [89] and voom [90], which estimates the mean variance trend of the log counts to predict the variance and to generate a precision weight to be incorporated in the linear model. Principal components analysis was performed using the voom-normalized data of the putative homologous genes from the 'Bluecrop' and 'Legacy' datasets identified using the reciprocal best blast hit (rbbh) method. Figures were plotted using the matplotlib and seaborn Python packages [91, 92] and VennDiagram package from $\mathrm{R}$ development Core Team [93]. Unigene annotation was performed using Interproscan, Blastp against the Uniprot Viridiplantae uniref 100 database (using a cut-off of e-value > $\left.1 * 10^{\wedge}-5\right)$, and assignment of gene ontology (GO) terms was performed with EggNOG (94). The distribution of GO functional classifications for the Unigenes was plotted with WEGO 2.0 using default parameters [95].

A double cutoff on both $p$-value and fold change was used to select differentially expressed genes and a $\mathrm{p}$-value $<0.001$ and a minimum logFC $>1$ were used to classify genes as differentially expressed. Three differential expression analyses were performed; one within each cultivar, and one between the 'Bluecrop' and 'Legacy' cultivars. The comparison performed between the 'Bluecrop' and 'Legacy' cultivars was carried out using the results of the rbbh analysis, with the 27,919 genes shared between the two cultivars. The significantly up- and down-regulated genes identified between 'Bluecrop' and 'Legacy' were grouped into four clusters using matplotlib in Python [91] representing genes up-regulated between harvest and post-harvest for both cultivars, genes down-regulated between harvest and post-harvest for both cultivars, genes up-regulated in 'Legacy' and down-regulated in 'Bluecrop' between harvest and post-harvest, and finally genes down-regulated in 'Legacy' and up-regulated in 'Bluecrop' between harvest and post-harvest. The functional annotations assigned to the differentially expressed unigenes were then scrutinised to identify differentially-expressed candidate unigenes with a potential role in regulating textural changes during post-harvest storage. Additionally, the Kyoto Encyclopedia of Genes and Genomes (KEGG) database (https://www.genome.jp/kegg/tool/map_pathway.html) was used to search and reconstruct the pathways of the differentially expressed genes from harvest to post-harvest in 'Bluecrop' and in 'Legacy'. The histogram of KEGG pathways was plotted using Excel.

The normalized expression levels of the candidate unigenes at harvest and post-harvest were used to plot a heat map with the heatmap3 package in R development Core Team [93].

\section{Comparison of unigenes with tetraploid blueberry gene predictions}

The 'Legacy' and 'Bluecrop' assembled unigenes were compared to the nucleotide sequence of the published tetraploid blueberry genome [22] with Blastn (BLAST + 2.7.1) using default parameters.

\section{Quantitative real-time PCR validation of RNAseq data}


cDNA was synthesised using the Omniscript reverse transcription kit (Qiagen, 205111) according to the manufacturer's recommendations with $500 \mathrm{ng}$ of high-quality RNA used in $20 \mu$ reactions. In total, four candidate genes with significant levels of differential expression in the RNAseq analysis and with relevant functions related to firmness changes during storage for both cultivars were selected for qRTPCR. These were: unigene_8556 (0-Acytransferase; down regulated in 'Legacy' and up regulated in 'Bluecrop'), unigene_22338 (Cytochome P450; up regulated in 'Legacy' and down regulated in 'Bluecrop'), unigene_20943 (Phloem protein like 2; up regulated in 'Legacy and in 'Bluecrop') and unigene_3134 (Glycoside hydrolase 17; down regulated in 'Legacy' and in 'Bluecrop'). In addition to this, eight stably expressed blueberry genes [96, 97] were selected for reference gene validation. These included: TIP41-like protein (TIP41); ubiquitin-conjugate enzyme (PEX4); hypothetical (Vc4g26410); unknown protein (Vc4g16320); glyceraldehyde 3-phosphate dehydrogenase (GAPDH); ubiquitin conjugating enzyme (UBC28); pentatricopeptide repeat-containing protein (PPR); and RNA helicase-like (RH8), which were tested in order to validate their expression stability under the conditions in this experiment. Validation of gene expression stability was carried out using the GeNorm software platform (https://genorm.cmgg.be/) $[98,99]$ and UBC28 and RH8, were selected as the most stable and were used as references for gene expression analyses.

Real time qRT-PCR primers (Table 3) for candidate genes were designed using the Primer3 web tool (http://primer3.ut.ee/), checked for primer dimer formation and secondary structures by OligoEvaluator ${ }^{\text {TM }}$ tool and verified in silico using the BLAST function of the Genome Database for Vaccinium spp (https://www.vaccinium.org/crop/blueberry) against the 'Bluecrop' and 'Legacy' unigene sets developed in this investigation and the Vaccinium predicted gene set (22). All qRT-PCR reactions were performed on a Bioer LineGene 9600 qRT-PCR system (Alpha laboratories, UK) using SYBR green as a detector dye. The PCR conditions used were as follows: $95^{\circ} \mathrm{C}$ for 3 minutes followed by 40 cycles of 30 seconds at $95^{\circ} \mathrm{C}$ and 1 minute at $60^{\circ} \mathrm{C}$. Candidate genes were validated in a total reaction volume of $20 \mu$ l containing $4 \mu \mathrm{l}$ of 1:15 diluted template $\mathrm{CDNA}, 1 \times \mathrm{XYBR}{ }^{\circledR}$ green master mix (Applied biosystems, UK), and $0.4 \mu \mathrm{M}$ of each forward and reverse primers, whilst for reference genes the reactions contained $0.15 \mu \mathrm{M}$ of each primer. Expression of each unigene was compared to the geometric mean of the two selected reference genes under harvest and post-harvest storage conditions. A total of three biological replicates of each cultivar and time point were performed, and the expression levels for each of the samples were calculated based on three technical replicates. 
Table 3

Primer sequences for the four unigenes used for qRT-PCR validation, including primer melting temperatures $\left(T_{m}\right)$, and reaction efficiencies $(E)$.

\begin{tabular}{|lllllc|}
\hline Unigene ID & Direction & Sequence & $\begin{array}{l}\text { Tm } \\
\left({ }^{\circ} \mathrm{C}\right)\end{array}$ & $\begin{array}{l}\text { Amplicon } \\
\text { size (bp) }\end{array}$ & $\begin{array}{c}\text { PCR E } \\
(\%)\end{array}$ \\
\hline Unigene_8556 & Forward & AAGGAAGTTTAGAGGCCCCG & 59.38 & 70 & 103 \\
\hline & Reverse & TGCTATGGTCGAGTTCTTCAAC & 58.41 & \\
\hline Unigene_22338 & Forward & ATCGGTGTCATCTTCGCAGC & 60.81 & 114 & \\
\hline & Reverse & GCCATCTTGTTCTTCGGTGAC & 59.54 & \\
\hline Unigene_20943 & Forward & GACAACTCCTCCACAGAAAAGC & 59.45 & 87 & \\
\hline & Reverse & CCCATCAACCCAATACTTCTTCTTC & 59.64 & \\
\hline Unigene_3134 & Forward & TTACAATGTGGGCCTCTCGG & 59.97 & 126 & \\
\hline & Reverse & CCCATCTTTGCTACCTTCGAAC & 59.32 & & \\
\hline
\end{tabular}

\section{Declarations}

\section{Ethics approval and consent to participate}

Not applicable

Consent for publication

Not applicable

\section{Availability of data and materials}

The datasets generated and analysed during the current study are available in the SRA repository under project number $\mathbf{X X X X X X X X X}$

\section{Competing interests}

The authors declare that they have no competing interests

\section{Funding}

MCC acknowledges a PhD grant from University of Greenwich Vice Chancellor Scholarship (VCS-ES-0817) and also acknowledges funding from Driscoll's Genetics Limited which covered the costs associated with field plots and molecular biology consumables in this investigation.

\section{Authors' contributions}


MCC carried out experimental work, data analysis and data interpretation, and authored the manuscript; DJS conceived the study, interpreted data and authored the manuscript; NŠ carried out experimental work, interpreted data and co-authored the manuscript; RJC conceived the study, interpreted data and authored the manuscript; MM conceived the study, analysed and interpreted data, and co-authored the manuscript. All authors read and approved the final manuscript.

\section{Acknowledgements}

We thank Ainhoa Rodríguez Pereira (Driscoll's Genetics Limited) for help with field work and Emma Cascant López (NIAB EMR) for her generous advice on laboratory protocols.

\section{References}

1. Retamales J, Hancock J. Blueberries. Blueberries. Cabi; 2012.

2. Joseph JA, Denisova NA, Arendash G, Gordon M, Diamond D, Shukitt-Hale B, et al. Blueberry supplementation enhances signaling and prevents behavioral deficits in an Alzheimer disease model.Nutritional Neuroscience. 2003;6:153-62.

3. Neto C. Cranberry and Blueberry: Evidence for protective effects against cancer and vascular Diseases. Mol. Nutr. Food Res. 2007;51:652-64.

4. Nixon RA. The role of autophagy in neurodegenerative disease. Nature Medicine. 2013;19:983.

5. Food and Agriculture Organization of the United Nations (FAO). http://www.fao.org/faostat/en/\#data. Accessed 17 Dec 2017.

6. Eurofruit. Fruitnet. 2017. http://www.fruitnet.com/eurofruit. Accessed 17 Dec 2017.

7. Giongo L, Poncetta P, Loretti P, Costa F. Texture profiling of blueberries (Vaccinium spp.) during fruit development, ripening and storage. Postharvest Biology and Technology. 2013;76:34-39.

8. Harker FR, Amos RL, Echeverría G, Gunson FA. Influence of texture on taste: Insights gained during studies of hardness, juiciness, and sweetness of apple fruit. Journal of Food Science. 2006;71(2):7782.

9. Chen L, Opara UL. Texture measurement approaches in fresh and processed foods - A review. Food Research International. 2013;51(2):823-35.

10. Forney C. Postharvest issues in blueberry and cranberry and methods to improve Market-Life. Acta Horticulturae. 2009; doi: 10.17660/ActaHortic.2009.810.105.

11. Moggia C, Beaudry R, Retamales J, Lobos G. Variation in the impact of stem scar and cuticle on water loss in highbush blueberry fruit argue for the use of water permeance as a selection criterion in breeding. Postharvest Biology and Technology. 2017;132:88-96.

12. Paniagua A, East A, Heyes J. Effects of delays in cooling on blueberry quality outcomes. Acta Horticulturae. 2013;1012:1493-8.

13. Paniagua A, East A, Hindmarsh J, Heyes J. Moisture loss is the major cause of firmness change during postharvest storage of blueberry. Postharvest Biology and Technology. 2013b;79:13-9. 
14. Vicente AR, Saladié M, Rose JK, Labavitch JM. The linkage between cell wall metabolism and fruit softening: looking to the future. J Sci Food Agric. 2007;87(8):1435-48.

15. Allan-Wojtas PM, Forney CF, Carbyn SE, Nicholas K. Microstructural Indicators of quality-related characteristics of blueberries-An integrated approach. LWT - Food Science and Technology. 2001;34(1):23-32.

16. Blaker KM, Olmstead JW. Stone cell frequency and cell area variation of crisp and standard texture southern highbush blueberry fruit. 2014;139(5):553.

17. Liu B, Wang K, Shu X, Liang J, Fan X, Sun L. Changes in fruit firmness, quality traits and cell wall constituents of two highbush blueberries (Vaccinium corymbosum L.) during postharvest cold storage. Scientia Horticulturae. 2019;246:557-62.

18. Verde I, Abbott AG, Scalabrin S, Jung S, Shu S, Marroni F, et al. The high-quality draft genome of peach (Prunus persica) identifies unique patterns of genetic diversity, domestication and genome evolution. Nature Genetics. 2013;45(5):487-94.

19. Velasco R, Zharkikh A, Troggio M, Cartwright DA, Cestaro A, Pruss D, et al. A high quality draft consensus sequence of the genome of a heterozygous grapevine variety. PLoS ONE. 2007;2(12):e1326.

20. Costich D, Ortiz R, Meagher T, Bruederle L, Vorsa N. Determination of ploidy level and nuclear DNA content in blueberry by flow cytometry. Theor Appl Genet. 1993;86(8):1001-1006.

21. Gupta V, Estrada AD, Blakley I, Reid R, Patel K, Meyer MD, et al. RNA-Seq analysis and annotation of a draft blueberry genome assembly identifies candidate genes involved in fruit ripening, biosynthesis of bioactive compounds, and stage-specific alternative splicing. Gigascience. 2015;4:5.

22. Colle M, Leisner CP, Wai CM, Ou S, Bird KA, Wang J, et al. Haplotype-phased genome and evolution of phytonutrient pathways of tetraploid blueberry. GigaScience. 2019;8(3).

23. Payá-Milans M, Nunez GH, Olmstead JW, Rinehart TA, Staton M. Regulation of gene expression in roots of the $\mathrm{pH}$-sensitive Vaccinium corymbosum and the $\mathrm{pH}$-tolerant Vaccinium arboreum in response to near neutral pH stress using RNA-Seq. BMC Genomics. 2017;18(1):580.

24. Li X, Sun H, Pei J, Dong Y, Wang F, Chen $H$, et al. De novo sequencing and comparative analysis of the blueberry transcriptome to discover putative genes related to antioxidants. Gene. 2012;511(1):5461.

25. Cappai F, Benevenuto J, Ferrão LFV, Munoz P. Molecular and genetic bases of fruit firmness variation in blueberry-A review. Agronomy. 2018;8(9):174.

26. Zhang F, Ji S, Wei B, Cheng S, Wang Y, Hao J, et al. Transcriptome analysis of postharvest blueberries (Vaccinium corymbosum 'Duke') in response to cold stress. BMC Plant Biol. 2020;20(1):80.

27. Chung SW, Yu DJ, Oh HD, Ahn JH, Huh JH, Lee HJ. Transcriptional regulation of abscisic acid biosynthesis and signal transduction, and anthocyanin biosynthesis in 'Bluecrop' highbush blueberry fruit during ripening. PLoS ONE. 2019;14(7):e0220015.

28. Rowland LJ, Alkharouf N, Darwish O, Ogden EL, Polashock JJ, Bassil NV, et al. Generation and analysis of blueberry transcriptome sequences from leaves, developing fruit, and flower buds from 
cold acclimation through deacclimation. BMC Plant Biology. 2012;12(1):46.

29. Prange R, DeEll J. Preharvest factors affecting postharvest quality of berry crops. HortScience. 1997;32:824-30.

30. Aghdam MS, Hassanpouraghdam MB, Paliyath G, Farmani B. The language of calcium in postharvest life of fruits, vegetables and flowers. Scientia Horticulturae. 2012;144:102-15.

31. Qi X, Ogden EL, Die JV, Ehlenfeldt MK, Polashock JJ, Darwish O, et al. Transcriptome analysis identifies genes related to the waxy coating on blueberry fruit in two northern-adapted rabbiteye breeding populations. BMC Plant Biology. 2019;19(1):460.

32. Wang S, Zhou Q, Zhou X, Zhang F, Ji S. Ethylene plays an important role in the softening and sucrose metabolism of blueberries postharvest. Food Chem. 2020;310:125965.

33. Wei J, Ma F, Shi S, Qi X, Zhu X, Yuan J. Changes and postharvest regulation of activity and gene expression of enzymes related to cell wall degradation in ripening apple fruit. Postharvest Biology and Technology. 2010;56(2):147-54.

34. Xie X-I, Yin X-r, Chen K-s. Roles of APETALA2/Ethylene-Response Factors in Regulation of Fruit Quality. Critical Reviews in Plant Sciences. 2016;35:1-11.

35. Edelmann $\mathrm{H}$, Neinhuis $\mathrm{C}$, Bargel $\mathrm{H}$. Influence of hydration and temperature on the rheological properties of plant cuticles and their impact on plant organ integrity. J Plant Growth Regul. 2005;24:116-26.

36. Lara I, Belge B, Goulao LF. The fruit cuticle as a modulator of postharvest quality. Postharvest Biology and Technology. 2014;87:103-12.

37. Matas Arroyo A, López-Casado G, Cuartero J, Heredia A. Relative humidity and temperature modify the mechanical properties of isolated tomato fruit cuticles. Am J Bot. 2005;92:462-8.

38. Moggia C, Graell J, Lara I, Schmeda-Hirschmann G, Thomas-Valdés S, Lobos GA. Fruit characteristics and cuticle triterpenes as related to postharvest quality of highbush blueberries. Scientia Horticulturae. 2016;211:449-57.

39. Bouzo CA, Gariglio NF. Relationship between different physical properties of tomato fruits and water loss during postharvest. Acta Sci. Pol. Hortorum Cultus. 2016;15(1):13-25.

40. Maalekuu B, Elkind Y, Tuvia-Alkalai S, Shalom Y, Fallik E. Quality evaluation of three sweet pepper cultivars after prolonged storage. Advances in Horticultural Science. 2003;17:187-91.

41. Romero P, Rose JKC. A relationship between tomato fruit softening, cuticle properties and water availability. Food Chemistry. 2019;295:300-10.

42. Li F, Wu X, Lam P, Bird D, Zheng H, Samuels L, et al. Identification of the wax ester synthase/acylcoenzyme. A:Diacylglycerol Acyltransferase WSD1 required for stem wax ester biosynthesis in Arabidopsis. Plant Physiology. 2008;148(1):97.

43. Suh MC, Samuels AL, Jetter R, Kunst L, Pollard M, Ohlrogge J, et al. Cuticular lipid composition, surface structure, and gene expression in Arabidopsis stem epidermis. Plant physiology. 2005;139(4):1649-65. 
44. Huang B-L, Li X, Liu P, Ma L, Wu W, Zhang X, et al. Transcriptomic analysis of Eruca vesicaria subs. sativa lines with contrasting tolerance to polyethylene glycol-simulated drought stress. BMC Plant Biology. 2019;19(1):419.

45. Chen $\mathrm{H}$, Cao S, Fang $\mathrm{X}, \mathrm{Mu} \mathrm{H}$, Yang $\mathrm{H}$, Wang $\mathrm{X}$, et al. Changes in fruit firmness, cell wall composition and cell wall degrading enzymes in postharvest blueberries during storage. Scientia Horticulturae. 2015;188:44-8.

46. Deng J, Shi Z, Li X, Liu H. Effects of cold storage and 1-methylcyclopropene treatments on ripening and cell wall degrading in rabbiteye blueberry (Vaccinium ashei) fruit. Food Sci Technol Int. 2014;20(4):287-98.

47. Konarska A. Morphological, anatomical, and ultrastructural changes in Vaccinium corymbosum fruits during ontogeny. Botany. 2015;93(9):589-602.

48. Chea S, Yu DJ, Park J, Oh HD, Chung SW, Lee H. Fruit softening correlates with enzymatic and compositional changes in fruit cell wall during ripening in 'Bluecrop' highbush blueberries. Scientia Horticulturae. 2019;245:163-70.

49. Costa F, Cappellin L, Fontanari M, Longhi S, Guerra W, Magnago P, et al. Texture dynamics during postharvest cold storage ripening in apple (Malus $\times$ domestica Borkh.). Postharvest Biology and Technology. 2012;69:54-63.

50. Zhang L, Chen F, Yang H, Sun X, Liu H, Gong X, et al. Changes in firmness, pectin content and nanostructure of two crisp peach cultivars after storage. LWT - Food Science and Technology. 2010;43(1):26-32.

51. Seymour GB, Ryder CD, Cevik V, Hammond JP, Popovich A, King GJ, et al. A SEPALLATA gene is involved in the development and ripening of strawberry (Fragariaxananassa Duch.) fruit, a nonclimacteric tissue. J Exp Bot. 2010;62(3):1179-88.

52. Vicente A, Costa M, Martínez G, Chaves A, Civello P. Effect of heat treatments on cell wall degradation and softening in strawberry fruit. Postharvest Biology and Technology. 2005;38:213-22.

53. Seymour GB, Chapman NH, Chew BL, Rose JKC. Regulation of ripening and opportunities for control in tomato and other fruits. Plant Biotechnol J. 2013;11(3):269-78.

54. Seymour GB, Colquhoun IJ, Dupont MS, Parsley KR, Selvendran RR. Composition and structural features of cell wall polysaccharides from tomato fruits. Phytochemistry. 1990;29(3):725-31.

55. Walker JA, Pattathil S, Bergeman LF, Beebe ET, Deng K, Mirzai M, et al. Determination of glycoside hydrolase specificities during hydrolysis of plant cell walls using glycome profiling. Biotechnol Biofuels. 2017;10(1):31.

56. Yeoman CJ, Han Y, Dodd D, Schroeder CM, Mackie RI, Cann IK. Thermostable enzymes as biocatalysts in the biofuel industry. Adv Appl Microbiol. 2010;70:1-55.

57. Asif MH, Lakhwani D, Pathak S, Gupta P, Bag SK, Nath P, et al. Transcriptome analysis of ripe and unripe fruit tissue of banana identifies major metabolic networks involved in fruit ripening process. BMC Plant Biology. 2014;14(1):316. 
58. Brummell DA. Primary cell wall metabolism during fruit ripening. New Zealand Journal of Forestry Science. 2006;36:99-111.

59. Boron AK, Van Loock B, Suslov D, Markakis MN, Verbelen J-P, Vissenberg K. Over-expression of AtEXLA2 alters etiolated arabidopsis hypocotyl growth. Annals of Botany. 2014;115(1):67-80.

60. Brummell DA, Howie WJ, Ma C, Dunsmuir P. Postharvest fruit quality of transgenic tomatoes suppressed in expression of a ripening-related expansin. Postharvest Biology and Technology. 2002;25(2):209-20.

61. Minoia S, Boualem A, Marcel F, Troadec C, Quemener B, Cellini F, et al. Induced mutations in tomato SIExp1 alter cell wall metabolism and delay fruit softening. Plant Sci. 2016;242:195-202.

62. Dotto MC, Martínez GA, Civello PM. Expression of expansin genes in strawberry varieties with contrasting fruit firmness. Plant Physiology and Biochemistry. 2006;44(5):301-7.

63. Nardi CF, Villarreal NM, Dotto MC, Ariza MT, Vallarino JG, Martínez GA, et al. Influence of plant growth regulators on Expansin2 expression in strawberry fruit. Cloning and functional analysis of FaEXP2 promoter region. Postharvest Biology and Technology. 2016;114:17-28.

64. Valenzuela-Riffo F, Ramos P, Morales-Quintana L. Computational study of FaEXPA1, a strawberry alpha expansin protein, through molecular modeling and molecular dynamics simulation studies. Computational Biology and Chemistry. 2018;76:79-86.

65. Hayama H, Ito A, Moriguchi T, Kashimura Y. Identification of a new expansin gene closely associated with peach fruit softening. Postharvest Biology and Technology. 2003;29(1):1-10.

66. Mitalo OW, Tokiwa S, Kondo Y, Otsuki T, Galis I, Suezawa K, et al. Low temperature storage stimulates fruit softening and sugar accumulation without ethylene and aroma volatile production in kiwifruit. Frontiers in Plant Science. 2019;10(888).

67. Marowa P, Ding A, Kong Y. Expansins: roles in plant growth and potential applications in crop improvement. Plant Cell Reports. 2016;35(5):949-65.

68. Bashline L, Lei L, li S, Gu Y. Cell Wall, Cytoskeleton, and Cell Expansion in Higher Plants. Molecular plant. 2014;7.

69. Fukuda H. Plant cell wall patterning and cell shape: Wiley Online Library; 2015.

70. Jin X, Yin X, Ndayambaza B, Zhang Z, Min X, Lin X, et al. Genome-Wide Identification and expression profiling of the ERF gene family in Medicago sativa L. Under Various Abiotic Stresses. DNA and Cell Biology. 2019;38(10):1056-68.

71. Licausi F, Ohme-Takagi M, Perata P. APETALA2/Ethylene responsive factor (AP2/ERF) transcription factors: mediators of stress responses and developmental programs. New Phytologist. 2013;199(3):639-49.

72. Mine T, Hiyoshi T, Kasaoka K, Ohyama A. CIP353 encodes an AP2/ERF-Domain protein in potato (Solanum tuberosum L.) and responds slowly to cold stress. Plant and Cell Physiology. 2003;44(1):10-5. 
73. Xie X-I, Yin X-r, Chen K-s. Roles of APETALA2/Ethylene-Response factors in regulation of fruit quality. Critical Reviews in Plant Sciences. 2016;35(2):120-30.

74. Rowland LJ. Construction of a genetic linkage map of an interspecific diploid blueberry population and identification of QTL for chilling requirement and cold hardiness. Mol breeding. 2014;v. 34(no. 4):pp. 2033-48-14 v.34 no.4.

75. Chakravarthy S, Tuori RP, D'Ascenzo MD, Fobert PR, Despres C, Martin GB. The tomato transcription factor Pti4 regulates defense-related gene expression via GCC box and non-GCC box cis elements. Plant Cell. 2003;15(12):3033-50.

76. Liu W, Zhao B-G, Chao Q, Wang B, Zhang Q, Zhang C, et al. The Maize AP2/EREBP transcription factor ZmEREB160 enhances drought tolerance in Arabidopsis. Tropical Plant Biol. 2020; https://doi.org/10.1007/s12042-020-09259-y.

77. Hejnowicz Z. Plants as Mechano-Osmotic Transducers. In: Wojtaszek P. (eds) Mechanical Integration of Plant Cells and Plants. Signaling and Communication in Plants, vol 9. Berlin:Springer; 2011. p. 241-267.

78. Iwanami H, Moriya S, Kotoda N, Abe K. Turgor closely relates to postharvest fruit softening and can be a useful index to select a parent for producing cultivars with good storage potential in apple. HortScience.2008; 43(5):1377-1381.

79. Hocking B, Tyerman SD, Burton RA, Gilliham M. Fruit Calcium: transport and physiology. Front Plant Sci. 2016;7:569.

80. Liu JC, Parks RJ, Liu J, Stares J, Rovira II, Murphy E, et al. The in vivo biology of the mitochondrial calcium uniporter. In: Santulli G, editor. Mitochondrial dynamics in cardiovascular medicine. Springer; 2017. p. 49-63.

81. Li Z, Wang L, Xie B, Hu S, Zheng Y, Jin P. Effects of exogenous calcium and calcium chelant on cold tolerance of postharvest loquat fruit. Scientia Horticulturae. 2020;269:109391.

82. Bolger AM, Lohse M, Usadel B. Trimmomatic: a flexible trimmer for Illumina sequence data. Bioinformatics. 2014;30(15):2114-20.

83. Chang Z, Li G, Liu J, Zhang Y, Ashby C, Liu D, et al. Bridger: a new framework for de novo transcriptome assembly using RNA-seq data. Genome Biology. 2015;16(1):30.

84. Li W, Godzik A. Cd-hit: a fast program for clustering and comparing large sets of protein or nucleotide sequences. Bioinformatics. 2006;22(13):1658-9.

85. Besemer J, Borodovsky M. GeneMark: web software for gene finding in prokaryotes, eukaryotes and viruses. Nucleic Acids Res. 2005;33(Web Server issue):W451-W454.

86. Camacho C, Coulouris G, Avagyan V, Ma N, Papadopoulos J, Bealer K, et al. BLAST+: architecture and applications. BMC Bioinformatics. 2009;10(1):421.

87. Langmead B, Salzberg SL. Fast gapped-read alignment with Bowtie 2. Nat Methods. 2012;9(4):357-9.

88. Liao Y, Smyth GK, Shi W. FeatureCounts: an efficient general purpose program for assigning sequence reads to genomic features. Bioinformatics. 2014;30(7):923-30. 
89. Smyth GK. limma: Linear Models for Microarray Data. In: Gentleman R, Carey VJ, Huber W, Irizarry RA, Dudoit S, editors. Bioinformatics and Computational Biology Solutions Using R and Bioconductor. New York, NY: Springer New York; 2005. p. 397-420.

90. Law CW, Chen Y, Shi W, Smyth GK. voom: precision weights unlock linear model analysis tools for RNA-seq read counts. Genome Biology. 2014;15(2):R29.

91. Hunter JD. Matplotlib: A 2D Graphics Environment. Computing in Science \& Engineering. 2007;9(3):90-5.

92. Waskom M, Botvinnik O, O'Kane D, Hobson P, Lukauskas S, Gemperlin DC, et al. mwaskom/seaborn: v0.8.1 (September 2017). Zenodo. 2017.

93. R development Core Team. R: A Language and Environment for Statistical Computing. Vienna, Austria: R Foundation for Statistical Computing; 2016.

94. Huerta-Cepas J, Szklarczyk D, Forslund K, Cook H, Heller D, Walter MC, et al. eggNOG 4.5: a hierarchical orthology framework with improved functional annotations for eukaryotic, prokaryotic and viral sequences. Nucleic Acids Res. 2016;44(D1):D286-93.

95. Ye J, Zhang Y, Cui H, Liu J, Wu Y, Cheng Y, et al. WEGO 2.0: a web tool for analyzing and plotting GO annotations, 2018 update. Nucleic Acids Research. 2018;46(W1):W71-W75.

96. Die JV, Rowland LJ. Superior cross-species reference genes: a blueberry case study. PLoS One. 2013;8(9):e73354.

97. Vashisth T, Johnson LK, Malladi A. An efficient RNA isolation procedure and identification of reference genes for normalization of gene expression in blueberry. Plant Cell Rep. 2011;30(12):216776.

98. Hellemans J, Mortier G, De Paepe A, Speleman F, Vandesompele J. Hellemans J, Mortier GR, De Paepe A, Speleman F, Vandesompele J. qBase relative quantification framework and software for management and automated analysis of real-time quantitative PCR data. Genome Biol. 2007;8:R19.

99. Vandesompele J, De Preter K, Pattyn F, Poppe B, Van Roy N, De Paepe A, et al. Accurate normalization of real-time quantitative RT-PCR data by geometric averaging of multiple internal control genes. Genome Biol. 2002;3(7):research0034.1.

\section{Figures}


(a)

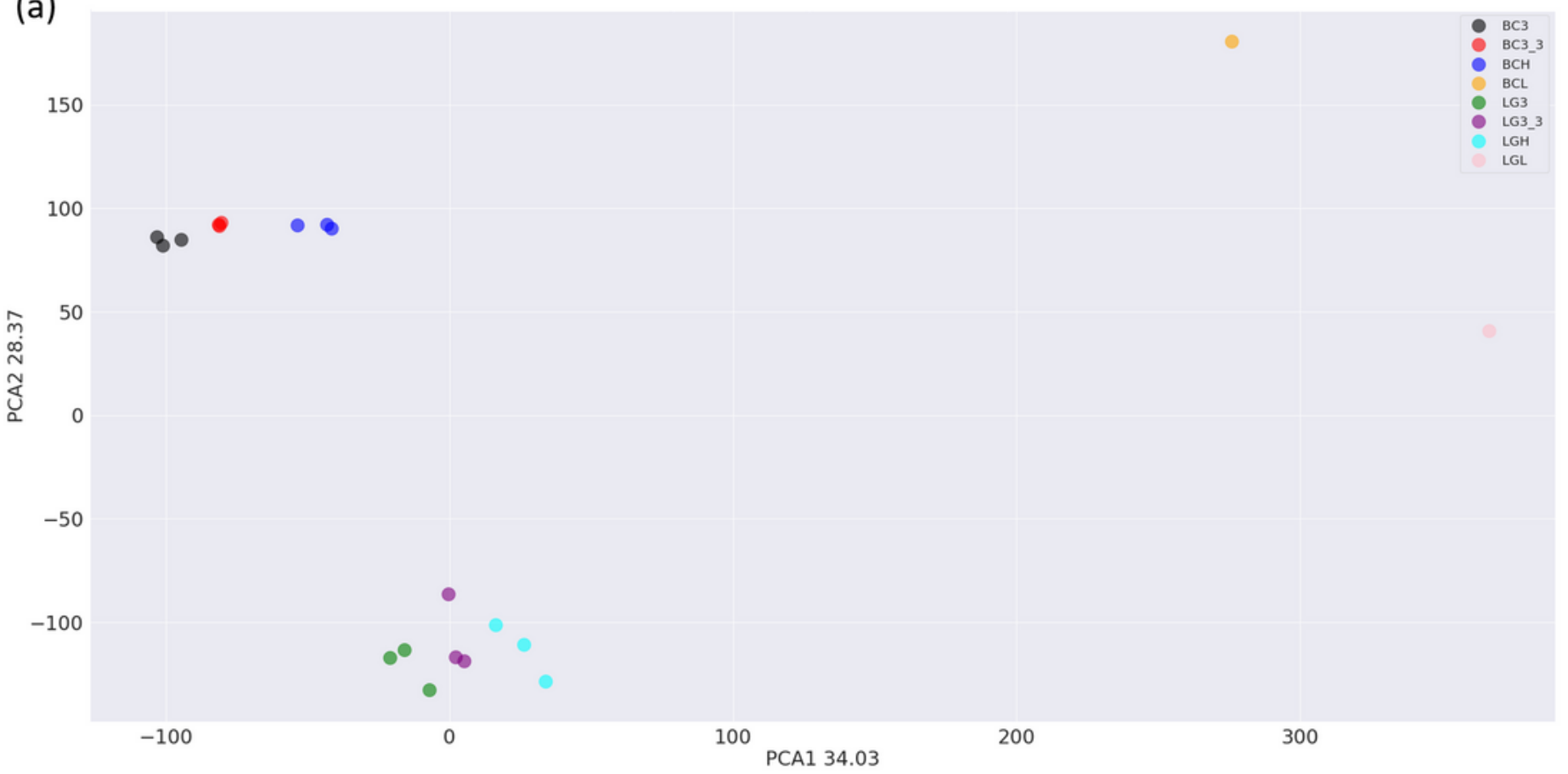

(b)

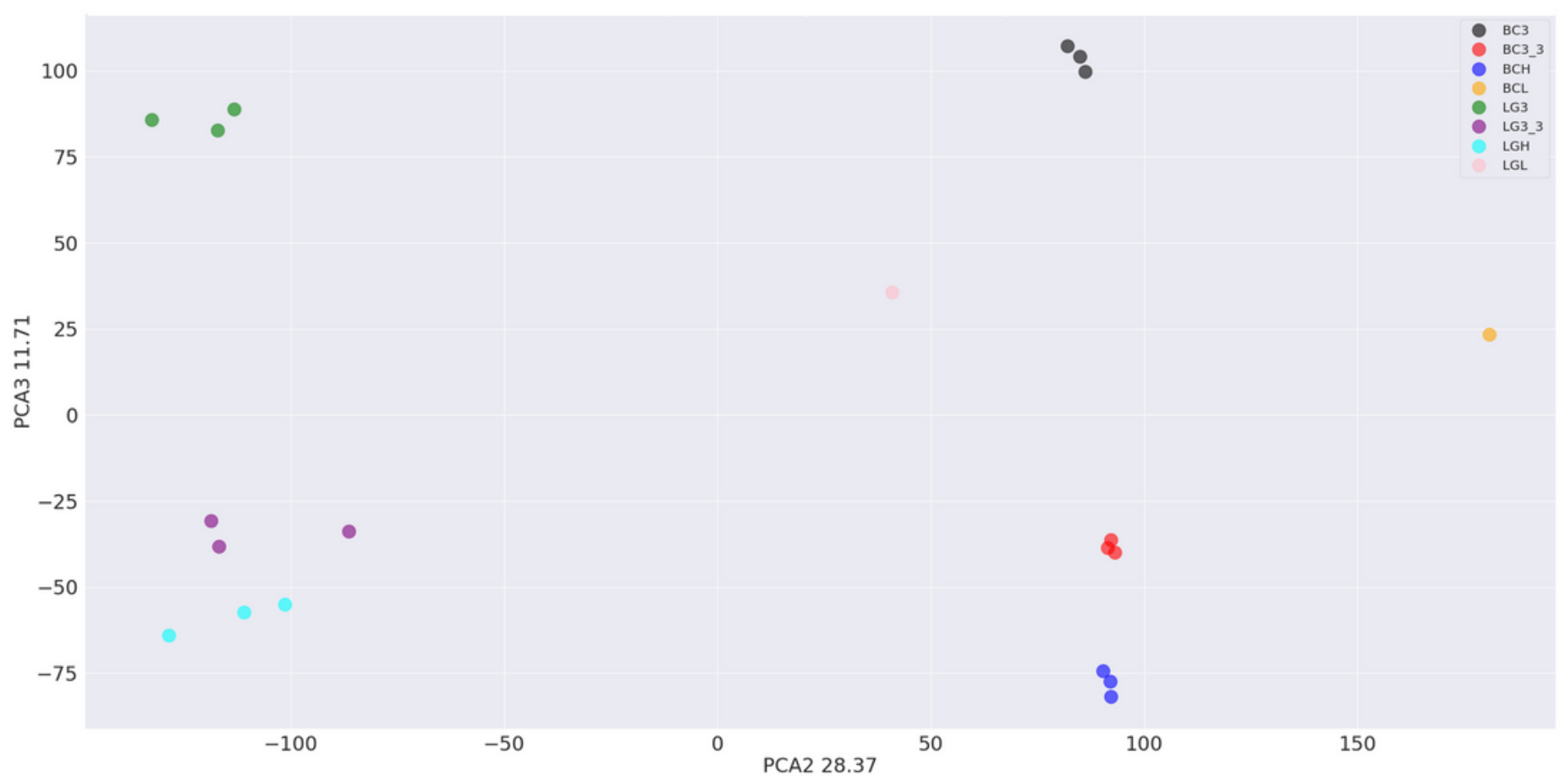

\section{Figure 1}

Principal component analysis showing (a) PCA1 and PCA2 (b) PCA3 and PCA4 for 'Bluecrop' and 'Legacy' fruit at harvest (BC-H and LG-H), 21 days postharvest (dph) at $4^{\circ} \mathrm{C}$ (BC-3 and LG-3) and $21 \mathrm{dpi}$ at $4^{\circ} \mathrm{C}$ followed by $3 \mathrm{dph}$ at $18^{\circ} \mathrm{C}(24 \mathrm{dph})$ (BC3_3 and LG3_3) as well as leaves (BCL and LGL). 


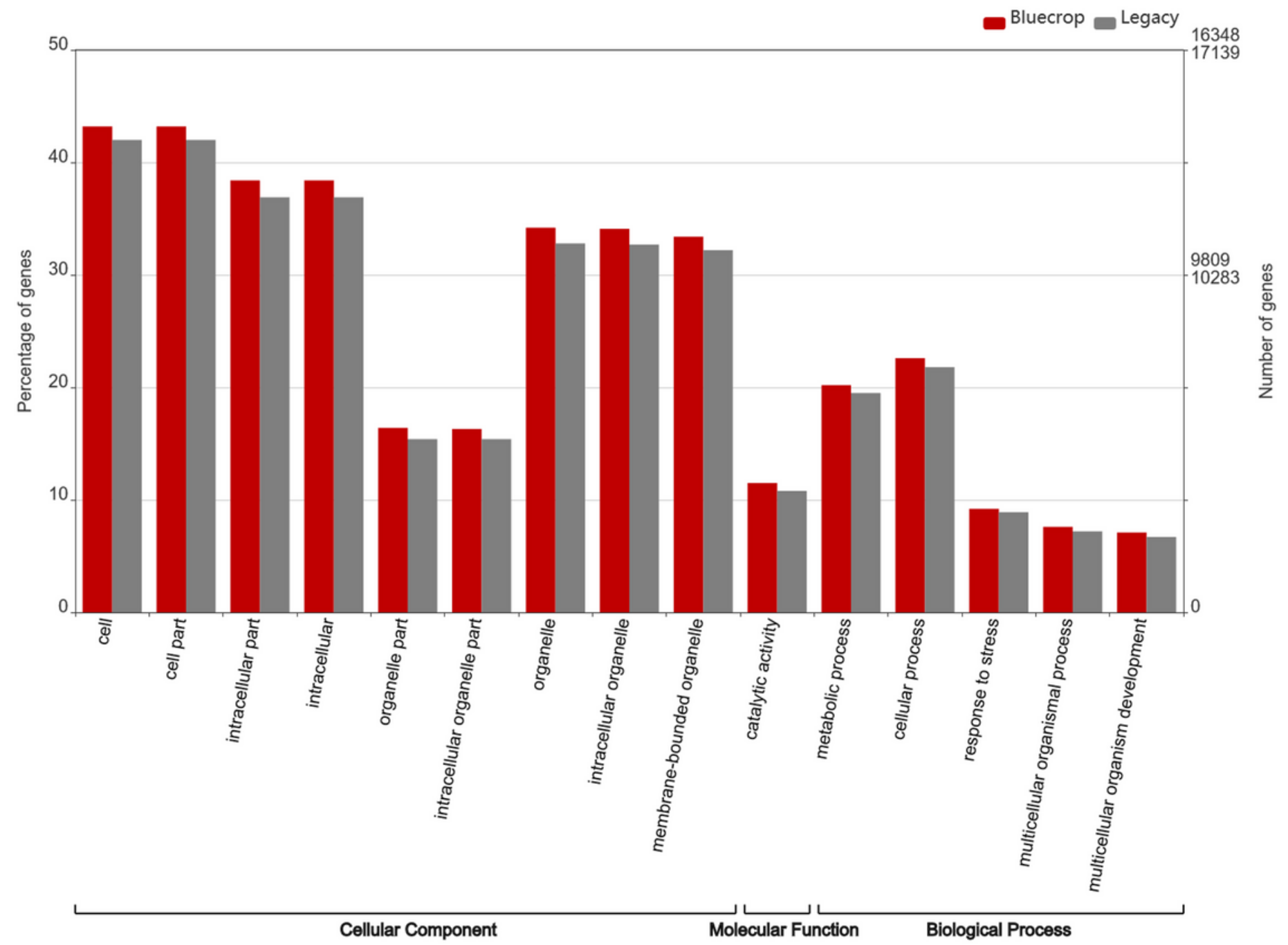

Figure 2

Gene Ontology (GO) functional classification of annotated unigenes for 'Bluecrop' (red) and 'Legacy' (grey) into cellular component, molecular function and biological processes categories. The main y-axis shows the percentage of unigenes annotated whilst the secondary $y$-axis details the number of unigenes annotated for 'Bluecrop' (black) and for 'Legacy' (light grey). 

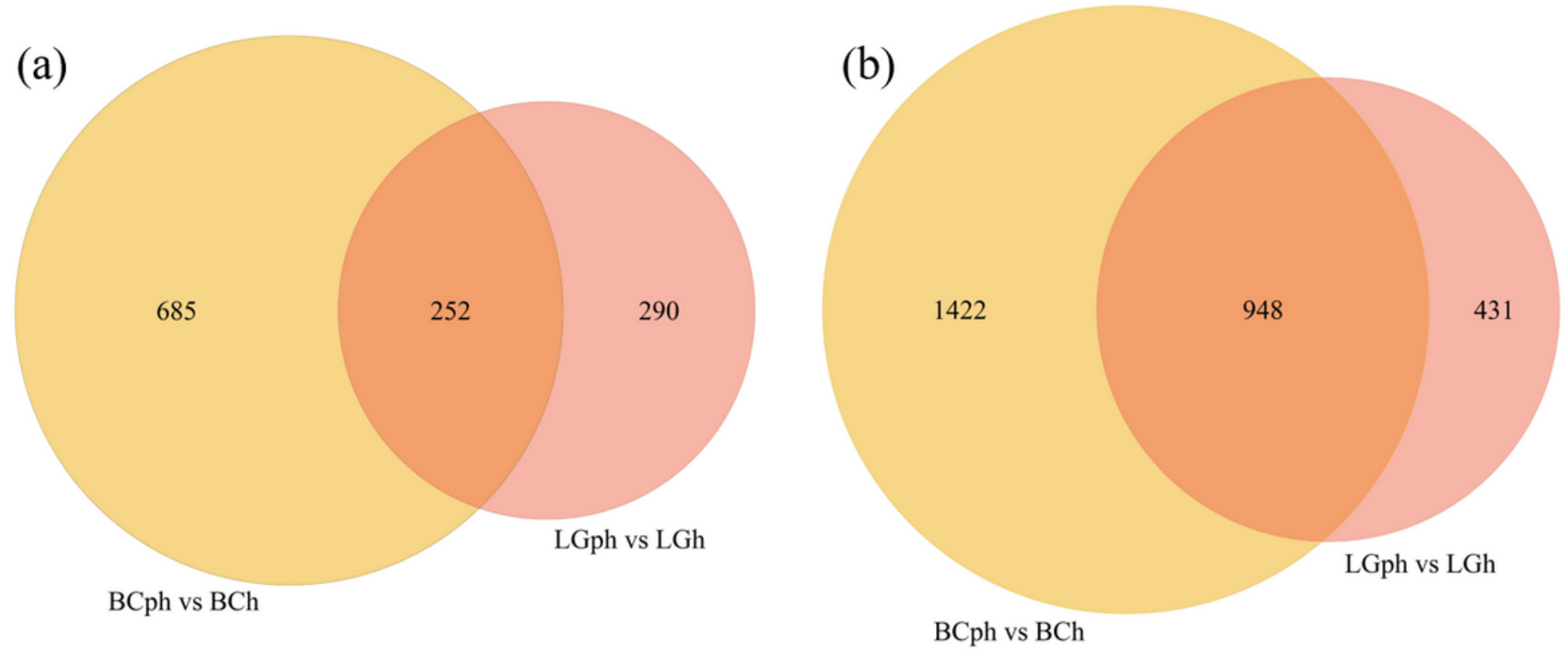

Figure 3

Venn diagram of (a) up-regulated DEGs and (b) down-regulated DEGs for 'Bluecrop' and 'Legacy' from harvest to $24 \mathrm{dph}$. BCh and LGh indicates 'Bluecrop' and 'Legacy' samples at harvest whilst BCph and LGph indicate 'Bluecrop' and 'Legacy' 24 dph samples.
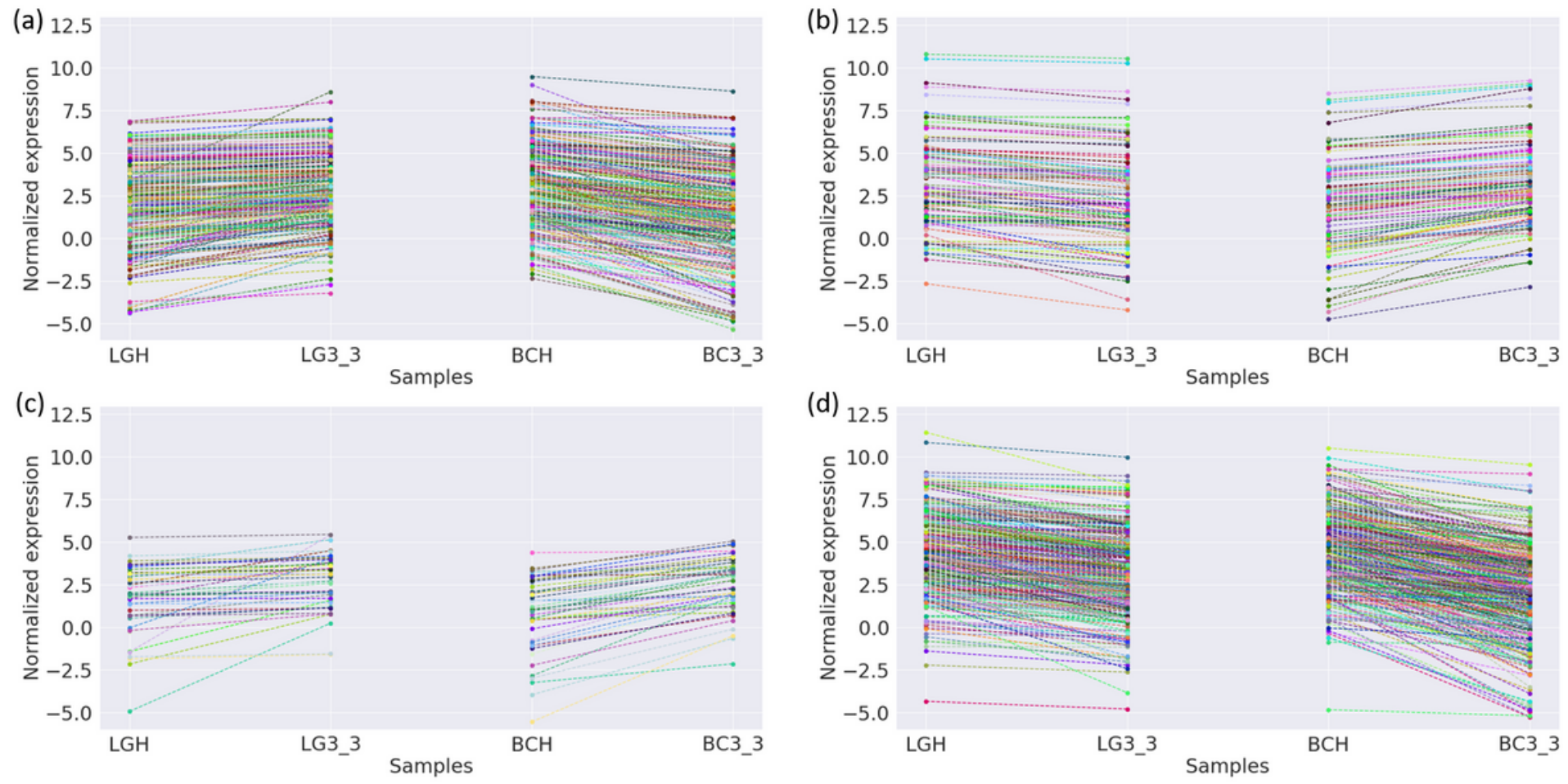

\section{Figure 4}


Clustering and classification of genes differentially-expressed within 'Bluecrop' and 'Legacy' into the four biological expression profiles (a) up-regulated in 'Legacy' and down-regulated in 'Bluecrop' (b) Downregulated in 'Legacy' and up-regulated in 'Bluecrop' (c) Up-regulated in both 'Legacy' and 'Bluecrop' (d) Down-regulated in both 'Legacy' and 'Bluecrop'. The labels LH and BC indicate 'Legacy' and 'Bluecrop' whilst $\mathrm{H}$ indicates samples from harvest and 3_3 indicates samples from 24 days post harvest.

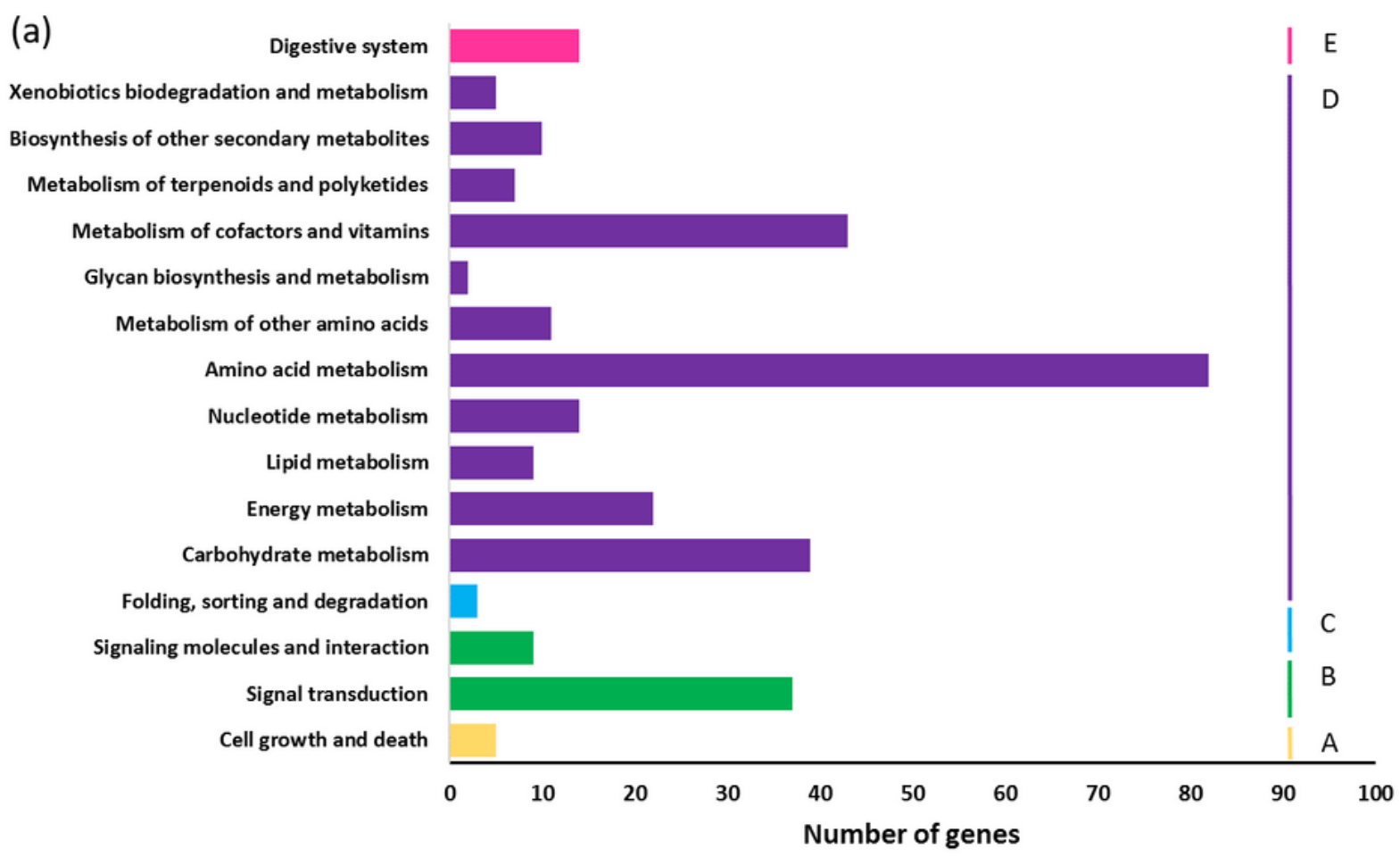

(b)

Digestive system

Xenobiotics biodegradation and metabolism

Biosynthesis of other secondary metabolites

Metabolism of terpenoids and polyketides

Metabolism of cofactors and vitamins

Glycan biosynthesis and metabolism

Metabolism of other amino acids

Amino acid metabolism

Nucleotide metabolism

Lipid metabolism

Energy metabolism

Carbohydrate metabolism

Folding, sorting and degradation

Signaling molecules and interaction

Signal transduction

Cellular processes
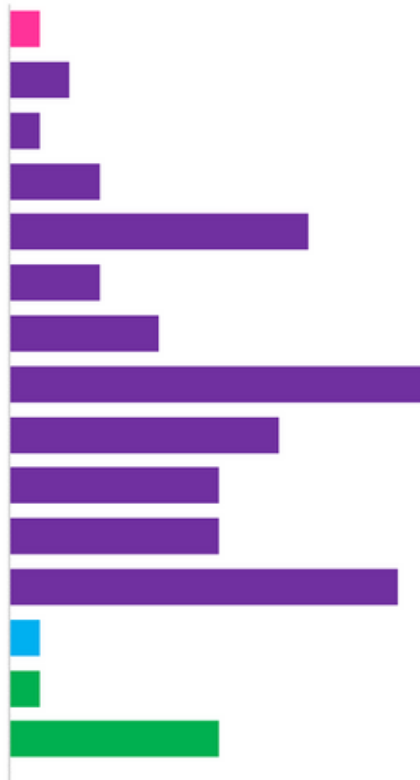

\begin{tabular}{lllccccc}
\hline 0 & 5 & 10 & $\begin{array}{c}15 \\
\text { Number of genes }\end{array}$ & & 25 & 30 & 35
\end{tabular}

Figure 5 
KEGG pathway annotation of DEGs in (a) 'Bluecrop' from harvest to $24 \mathrm{dph}$, and (b) 'Legacy' from harvest to $24 \mathrm{dph}$. The $x$-axis shows the number of unigenes annotated and the $y$-axis details the KEGG pathway category. A) Cellular processes, B) Environmental information processing, C) Genetic information, D) Metabolism and E) Organismal systems.
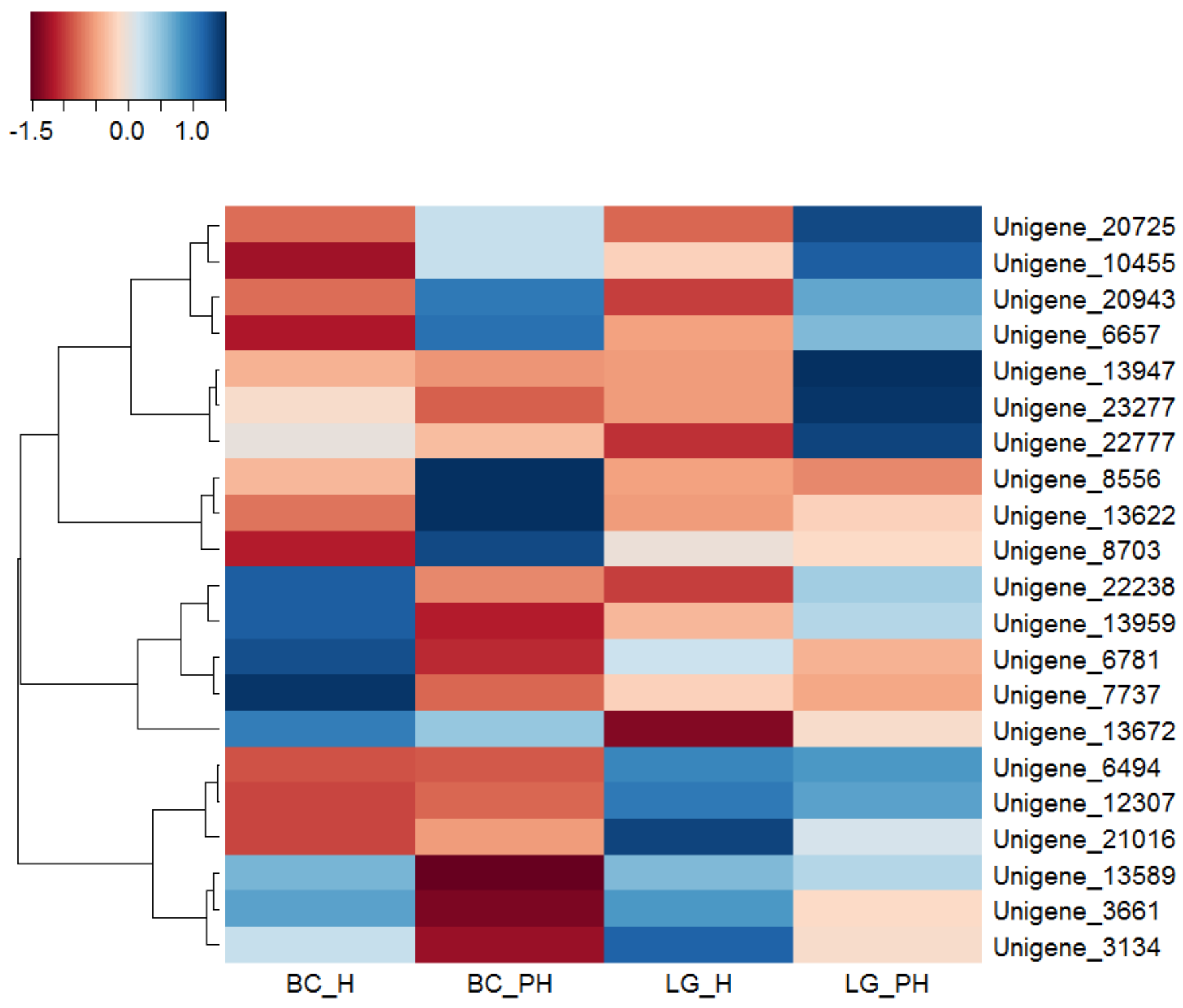

\section{Figure 6}

Heat map showing the expression of the 21 candidate unigenes identified as having a potential role in regulating changes in post-harvest firmness in 'Bluecrop' and 'Legacy'. The colour scale represents FPKM normalized expression levels, the rows represent each unigene and the columns represent each cultivar and time point. BC indicates 'Bluecrop', LG indicates 'Legacy', $\mathrm{H}$ indicates harvest and PH indicates 24 days post-harvest. 
(a)

nNAseq a qRT-PCR

4

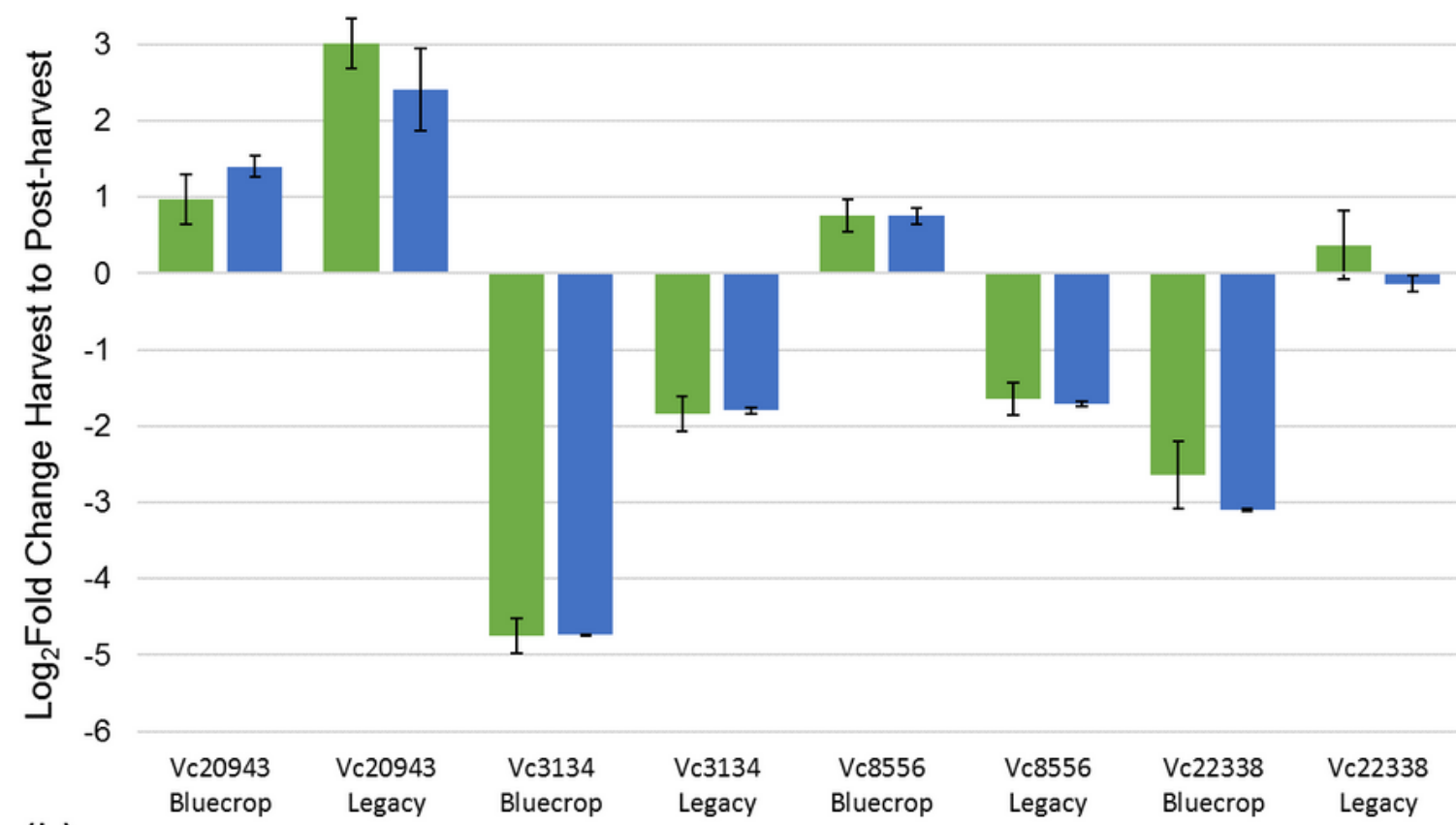

(b)

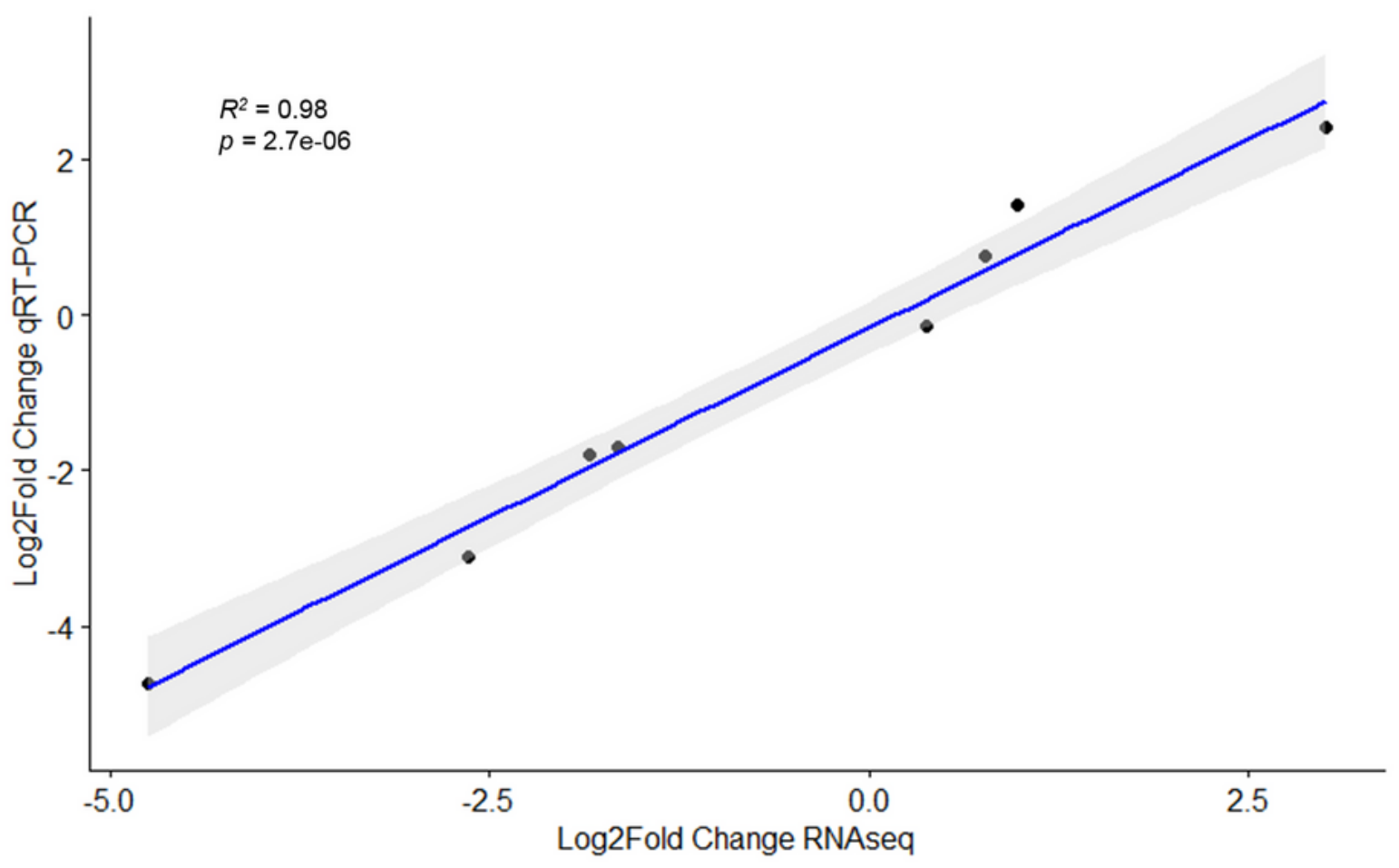

Figure 7

(a) Comparison of the relative expression levels obtained by RNAseq and qRT-PCR for each of the unigenes selected for experimental validation as Log2 fold-change from harvest to $24 \mathrm{dph}$ for each unigene. The $x$-axis represents each unigene cultivar combination and the $y$-axis represents the Log2 foldchange from harvest to $24 \mathrm{dph}$. (b) Correlation between RNAseq and qRT-PCR (as log2 fold change ratio 
of relative expression at harvest and $24 \mathrm{dph}$ in 'Bluecrop' and 'Legacy') showing the Pearson correlation coefficient and p-values.

\section{Supplementary Files}

This is a list of supplementary files associated with this preprint. Click to download.

- Additionalfile1.docx

- Additionalfile2.xlsx 